\title{
La occidentalización de la arquitectura rusa. Perspectiva desde cuatro estadios del Mundial de fútbol FIFA Rusia 2018*
}

\author{
The westernization of Russian architecture. \\ Perspective from four stadiums of the FIFA World Cup Russia 2018
}

\author{
César Castañeda** \\ Universidad Nacional de ingeniería \\ Recibido: 22 de junio de 2019 \\ Aceptado: 26 de julio de 2019
}

\begin{abstract}
RESUMEN
El fútbol, con el impulso de la globalización, se ha convertido en el deporte con mayor impacto socio-económico a nivel mundial, por su enorme audiencia y por el sistema tecnológico, digital y comercial creado a su alrededor, más allá de lo exclusivamente deportivo. En este sentido, la arquitectura de los estadios refleja dichas transformaciones desde modelos racionales de construcción hacia objetos escultóricos-digitales.

El Mundial de Rusia 2018, como magno evento deportivo, permite revisar las condiciones de inserción arquitectónica de una nación que añora volver a situarse como potencia y que ha tenido que incorporarse forzosamente a una economía capitalista de la que fue, durante décadas, ajena y crítica.

Los estadios analizados de cuatro ciudades distintas y lejanas (Saransk, Ekaterimburgo, Sochi y Moscú) permiten entender el accionar de las firmas diseñadoras, sus lógicas proyectuales, los objetos creados y la necesidad de lograr edificios tecnológicos de gran impacto. Todo eso en relación a un lugar geográfico y cultural como Rusia, con la incertidumbre que plantea la acelerada aceptación de lo globalizado en un país de arraigo tradicional.
\end{abstract}

Palabras clave: Rusia, Unión Soviética, Mundial de fútbol Rusia 2018, globalización, arquitectura deportiva, imagen, tecnología.

\section{ABSTRACT}

Football soccer, with the growth of globalization, has become the sport with the greatest socio-economic impact worldwide, due to its huge audience and the technological, digital and commercial system created around it, beyond of exclusively sportive. In this way, the architecture of the stadiums reflects these transformations from rational models of construction to sculptural-digital objects.

The 2018 World Cup in Russia, as a great sports event, allows us to review the conditions of architectural insertion of a nation that longs to return as a world power and that has had to forcefully join a capitalist economy of which it was, for decades, foreign and critical.

The analyzed stadiums of four different and distant cities (Saransk, Yekaterinburg, Sochi and Moscow) allow us to understand the actions of the design firms, their project logic, the objects created and the need to achieve high-impact technological buildings. All this is in relation to a geographical and cultural place like Russia, with the uncertainty posed by the accelerated acceptance of the globalization in a country with traditional roots.

Keywords: Russia, Soviet Union, World Cup Russia 2018, globalization, sports architecture, image, technology.

* Antecedentes del documento. Este artículo es el resultado en la exploración de una triada de pasiones personales como son el fútbol, la dromomanía y la historia desde la visión de un arquitecto. Dedicado a c.g.g.v.

** César Castañeda Silva. Arquitecto (Universidad Nacional de Ingeniería). Egresado de la Maestría en Arquitectura -Historia, Teoría y Crítica de la Escuela de Posgrado-FAUA-UNI. 


\section{Introducción}

El Mundial de fútbol FIFA Rusia 2018 no solo ha significado para el fútbol peruano el retorno a este importante evento 36 años después, sino que también definió en nuestra sociedad una muestra importante de identificación y orgullo de lo que denominamos peruanidad, puesto de manifiesto cada vez que este deporte permite situaciones de reconocimiento. Como forma de expresión cultural y social traducida en efervescencia, orgullo y valoración de nacionalismos, el fútbol también ha sido excusa para el entrometimiento político. ${ }^{1}$ Esta cita deportiva, que convocaría en tierras rusas a más de 50000 peruanos, más allá de la experiencia futbolística permitió inusitados intercambios culturales $y$, de alguna manera, poder indagar sobre los incógnitos modos de vida y formas de gobierno de la recóndita Europa del Este.

En nuestro caso, desde el ámbito arquitectónico, era un anhelo recorrer las coloridas y tradicionales iglesias ortodoxas con techos de cúpula bulbosa, las viviendas realizadas en madera como respuesta al lugar y la inclemencia del frío, las búsquedas teóricas de las vanguardias de inicios del siglo XX, la arquitectura monumental de la era stalinista y esencialmente el modo sobre el cual la arquitectura rusa se ha mostrado en el siglo XXI desde la incorporación del capitalismo y la globalización a su sistema político, social y económico. (Figuras 1, 2 y 3) Sobre esta condición, se reconoce la actualidad a partir de cuatro estadios visitados sobre los doce elegidos para el evento, ${ }^{2}$ diez de ellos construidos en los últimos 5 años y 2 remodelados, situándolos desde sus condiciones estéticas, su temporalidad y demás características que puedan definir sus formas de interpretar el cambio traumático post-soviético hacia lo globalizado. (Figura 4) En ellos se pueden verificar nuevos modos de proyectar y la superposición de lo fenomenológico, tecnológico o comunicacional, más cercanas a la arquitectura débil o líquida, desde la continuidad de lógicas revisadas y actualizadas en su discurso. ${ }^{3}$
Arquitectura, política y sociedad. El antecedente soviético

Si alguna característica definió a la arquitectura y el arte durante la era soviética ${ }^{4}$ es la indisociable relación entre los modos de pensamiento con los hechos sociales y políticos, sobre las duras condiciones desarrolladas en el territorio, sumido en la destrucción y reconstrucción de ciudades inmersas en conflictos bélicos, revoluciones, guerras civiles y dictaduras. Esto, llevado a la arquitectura, se reflejaría en las principales ciudades soviéticas (Leningrado, Stalingrado, Kiev, Moscú) condicionadas al poder del Estado, esquivo a toda influencia externa para sus edificaciones públicas. En la reconstrucción de las ciudades conviven, sin embargo, con arquitectura de menor escala, como viviendas citadinas y rurales, que sostienen procesos paralelos en relación con paisajes, geografías y climas, muy diversos y extremos, que condicionan modos de vida con características vernaculares. ${ }^{5}$ (Figura 5)

En este sentido, podríamos definir cuatro periodos de la arquitectura pública durante la etapa soviética (1922-1991). ${ }^{6} \mathrm{EI}$ primer periodo se refiere al nacimiento de las vanguardias, que sostenían el contenido estético y artístico en la técnica y la racionalidad. "El constructivismo de Malevich y Lissitzky intentaba representar las formas constructivas puras, partían de la ponderación de formas sin más ideología que los materiales y las técnicas apropiadas para su materialización." (Bernardele, 2009, p.186) Esto llegaría a la arquitectura a modo de utopías y modelos ideales basados en la abstracción, la geometría y la funcionalidad, alejados de lo ornamental y tradicional. Esto fue posible en un breve instante de entusiasmo, apertura de pensamiento y ruptura con el pasado, producido por la revolución bolchevique y las reformas del proletariado ante el Zarismo, así como en las nuevas condiciones de vida definidas por el comunismo. (Figura 6) 


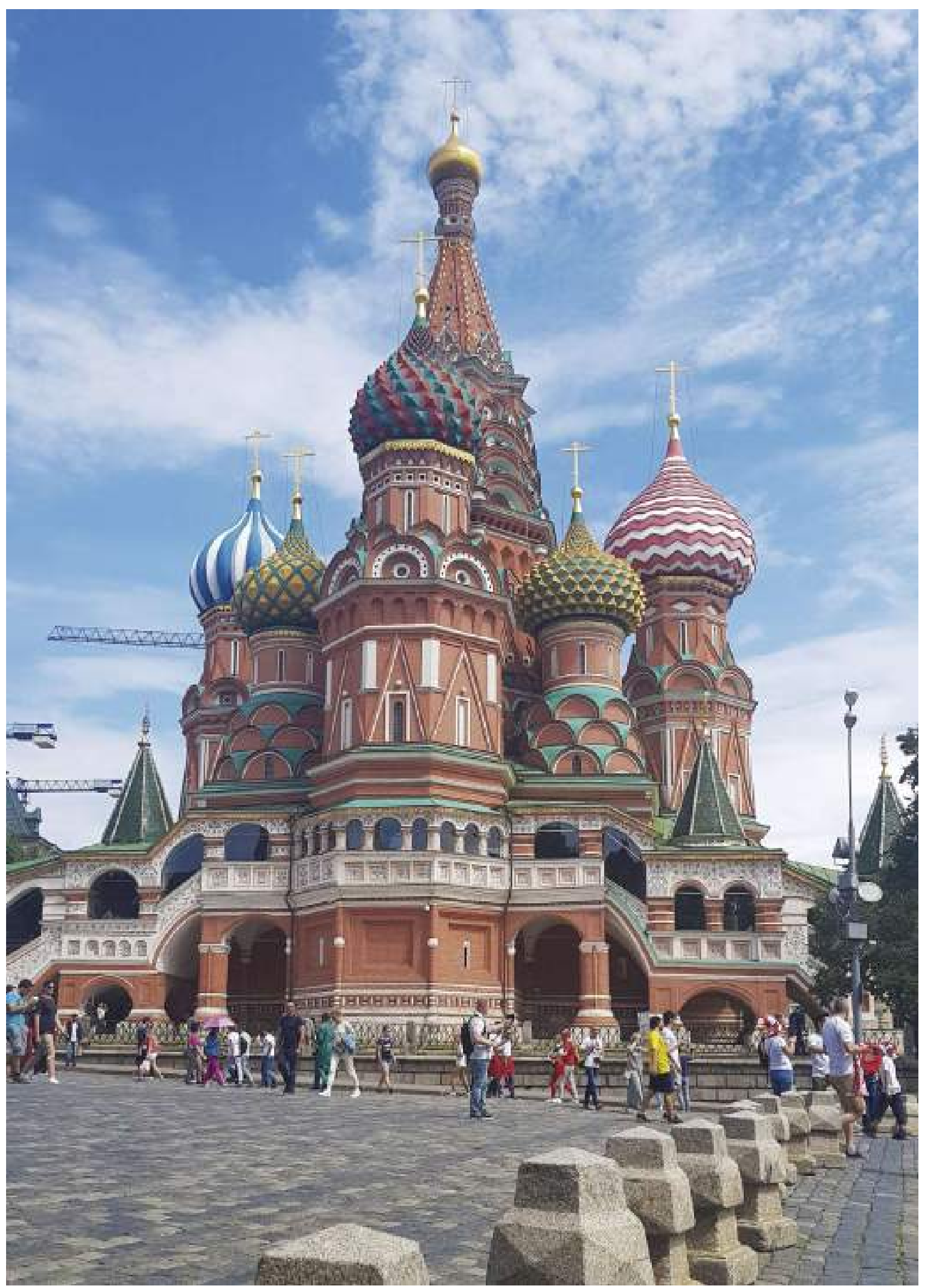

Figura 1. Catedral de San Basilio, siglo XVI, Plaza Roja de Moscú. Foto: C. Castañeda, 2018. 


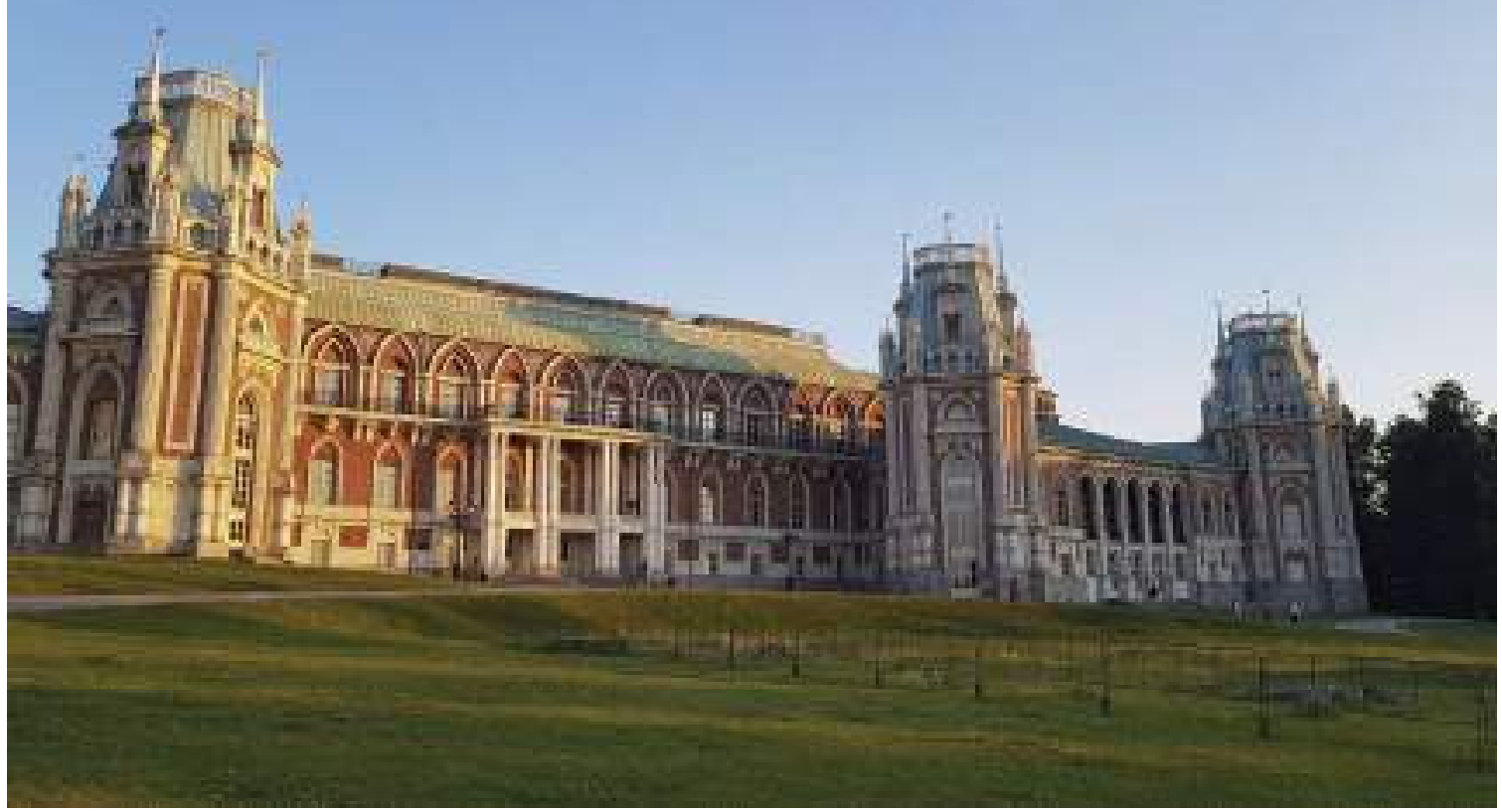

Figura 2. Palacio Tsarítsino, siglo XVIII, ubicado en la parte suroeste de Moscú. Foto: C. Castañeda, 2018.

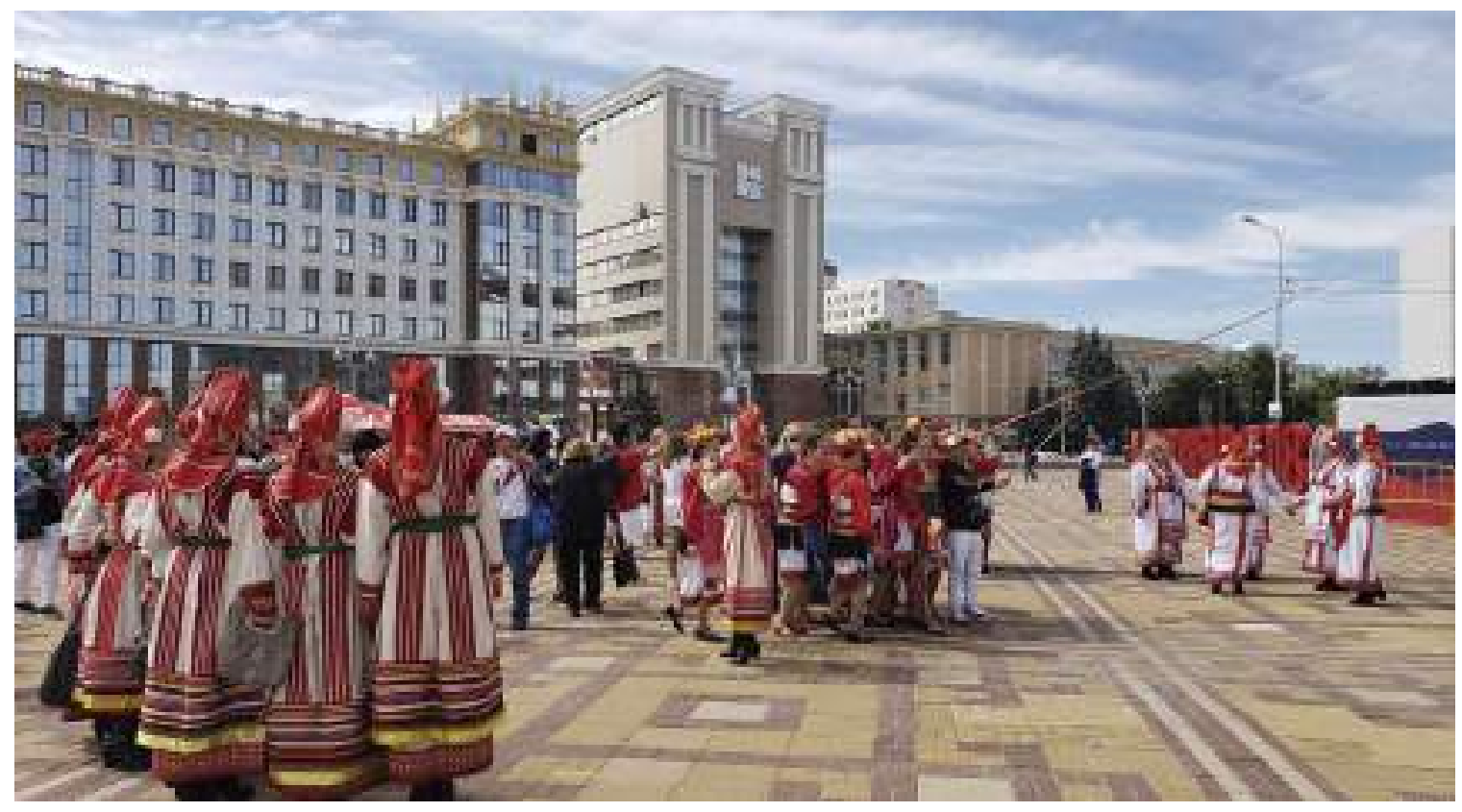

Figura 3. Ploshchad' Tysyacheletiya (Plaza del Milenio), inaugurada en el año 2012. Saransk. Foto: C. Castañeda, 2018.

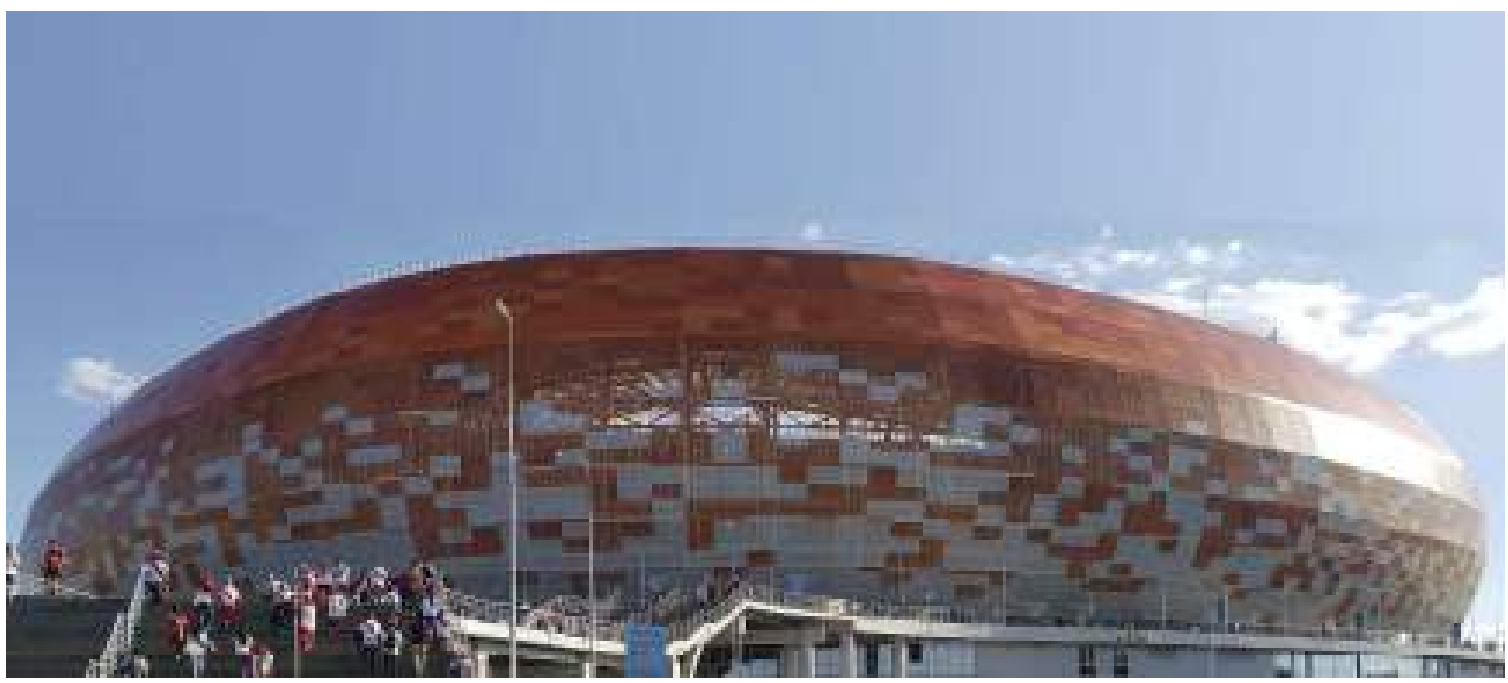

Figura 4. Mordovia Arena de Saransk, culminado con ocasión del Mundial FIFA Rusia 2018. Foto: C. Castañeda, 2018. 
La segunda etapa, entre 1930 y 1950, tiene directa relación con el gobierno de Joseph Stalin ${ }^{7}$ quien definió los modos de realización arquitectónica desde el monumentalismo, expresado en sus principales edificaciones y avenidas, institucionalizando el art-decó, el neoclasicismo y el academicismo como estilos que se verán reflejados en el megaproyecto denominado "Las siete hermanas". (Figura 7)

La tercera etapa comprende desde mediados de la década de 1950 hasta los años de 1970, desarrollados en medio de la guerra fría, teniendo en Nikita Kruschev al líder político que flexibilizó el ingreso y salida del país, el intercambio cultural desde el arte y la reestructuración educativa. Frente a la crisis de habitabilidad y el hacinamiento consecuencia de la segunda guerra mundial, hizo de la vivienda una prioridad en la reconstrucción nacional. De este modo, una vez más la arquitectura estuvo sujeta a las decisiones del Estado, implementándose la construcción masiva de estrechos bloques de vivienda racionales, pequeños y similares entre sí, donde se concentraría la cuarta parte de la población.

Finalmente, la cuarta etapa (19641982) devino del estancamiento del gobierno de Kruschev, que desataría la crisis del comunismo en las décadas de 1980 y 1990, lo que acarrearía la disolución de la URSS y la aparición de nuevos estados, que antes se regían por la ideología socialista. En esta época, sin embargo, se darían en la arquitectura soviética escasas pero sugerentes realizaciones de índole formalista, expresiva y monumental, pero que evidenciaban procesos tardíos con respecto a occidente.

A pesar de haber iniciado el siglo $X X$ con una nueva visión de sociedad, post-revolución bolchevique, de estructurar tendencias como el constructivismo y el suprematismo, ligadas a la abstracción y el racionalismo (que en occidente establecerían las bases de la arquitectura moderna), esta quedó relegada como discurso y práctica, situando a la arquitectura soviética en un letargo ideológico y atemporal, sujeta a gustos y necesidades conserva-

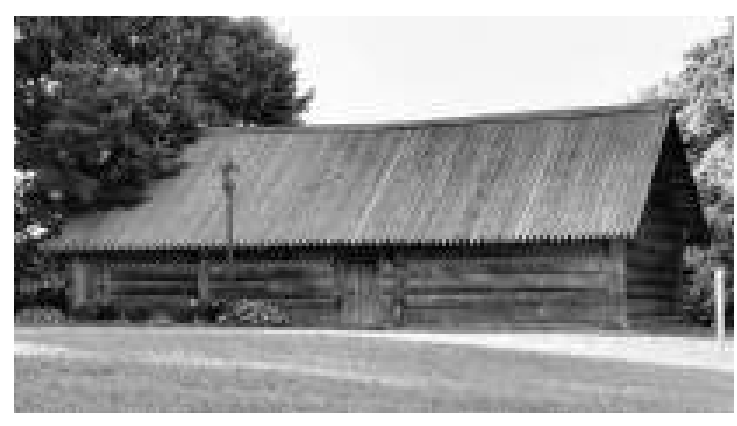

Figura 5. Vivienda rural del tipo isba, en Kolomenskoye, a las afueras del sur de Moscú. Foto: C. Castañeda, 2018.

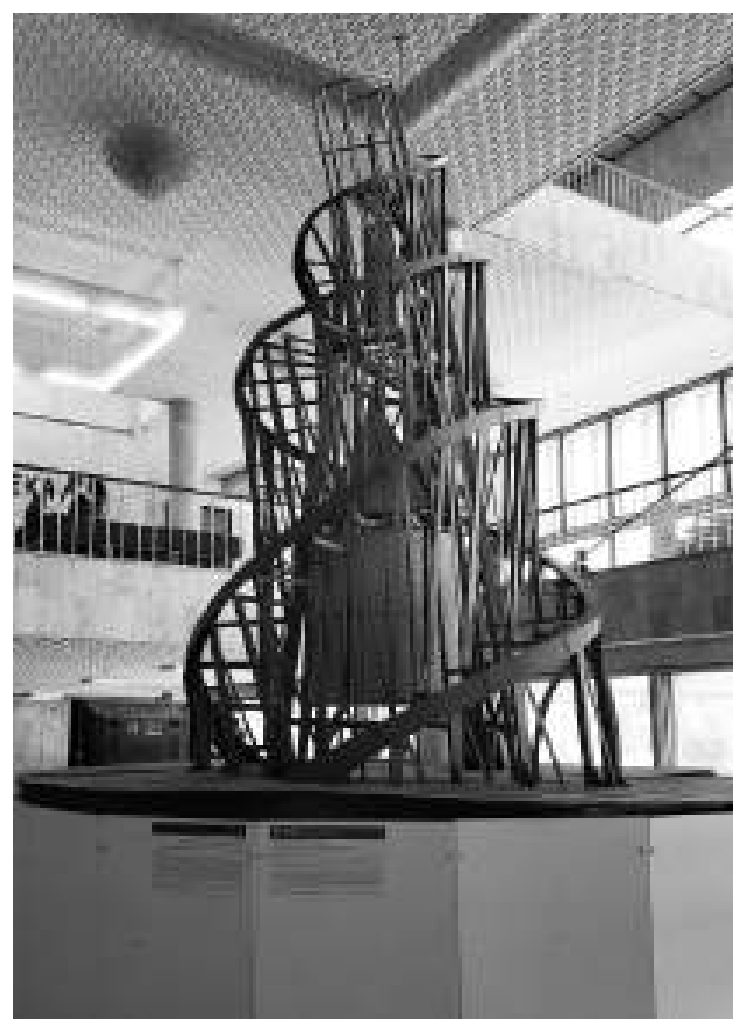

Figura 6. Modelo del Monumento a la III Internacional, de Vladimir Tatlin, Proyecto no ejecutado, Petrogrado 1919. Medidas: 264 x 496. Escultura mostrada en la Nueva Galería TretiakovMuseo de Arte Moderno en Moscú. Reconstruida en 1993 por D. Dinakov, E. Lapshina, I. Fedotov. Foto: C. Castañeda, 2018.

doras de los jefes de Estado, así como a la difícil tarea de reconstruir las ciudades luego de las dos guerras mundiales. No obstante, esto no afecta la autenticidad de la arquitectura doméstica que se realiza tanto en el ámbito citadino como rural. Ella se mantiene inalterable desde la tradición, al definirse por la necesidad y las condiciones extremas del clima, ajena a los procesos que derivarían en la crisis del comunismo. 


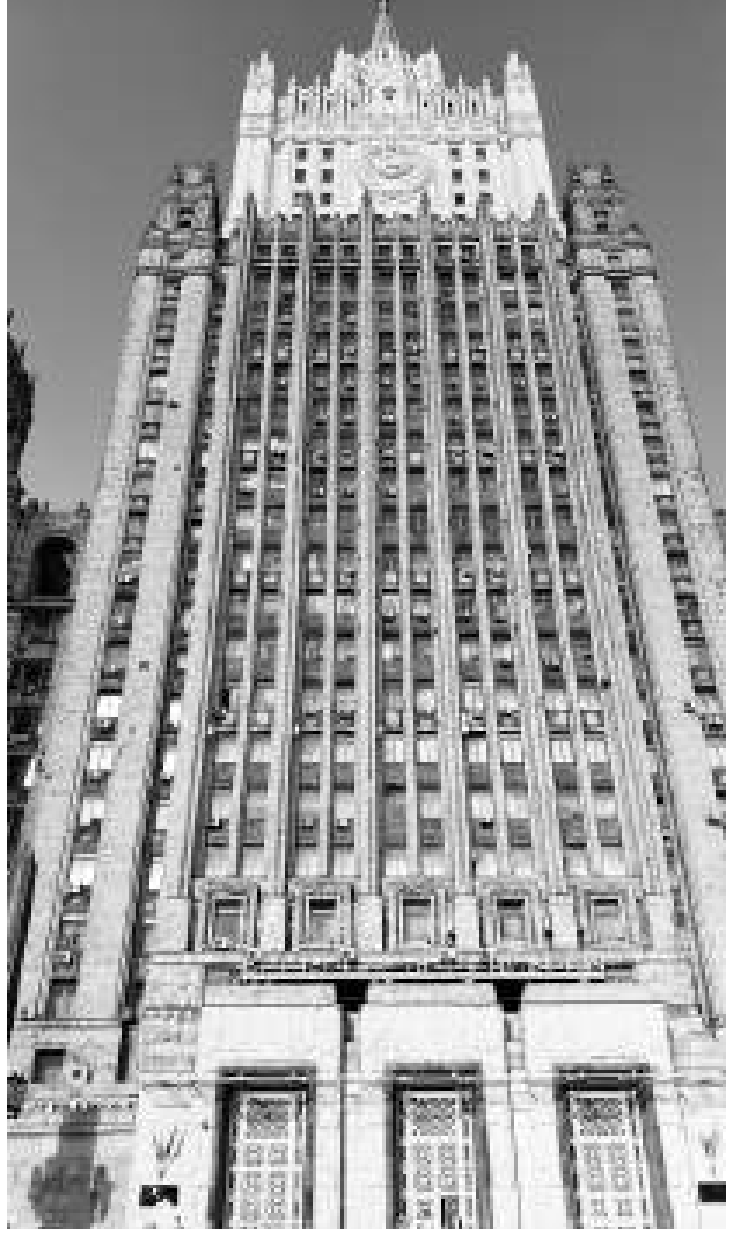

Figura 7. Ministerio de Asuntos Exteriores de Rusia, Moscú, 1953. Uno de los siete rascacielos construidos durante el gobierno de Stalin, tiene una altura de 172 metros y actualmente funciona como Ministerio de Relaciones Exteriores y de Comercio. Foto: C. Castañeda, 2018.

\section{Arquitectura rusa durante la inserción global}

El fin del comunismo en la política de la Unión Soviética permitió la apertura hacia una economía de libre mercado, el derecho a la propiedad privada, intercambios culturales con los países de Europa occidental, la desintegración de las repúblicas soviéticas y un nuevo modelo de vida basado en el consumo. Para la sociedad rusa, acostumbrada a la subvención estatal, la unidad familiar y el orgullo de la Gran Madre Patria, significa un proceso de inserción a la globalización como algo extraño a sus valores, costumbres y tradiciones, a la que se denomina la nostalgia post-soviética. ${ }^{9}$

La perestroika y la glasnost, encaminadas durante el gobierno de Mijaíl Gorbachov (1988-1991) señalaron el camino de la reestructuración económica y la transparencia políti- ca, así como los primeros lazos con el mundo occidental mediante reformas. A pesar de los cambios, estas fueron percibidas como lentas, que no fueron solución al caos y el anquilosamiento; a lo que se sumó la corrupción, el enriquecimiento de una minoría oligárquica y las revueltas sociales durante el periodo de Boris Yeltzin (1991-1999), lo que culminaría abruptamente en su renuncia dando paso a la presidencia interina de Vladimir Putin (1999-2000).

Fue una primera década de crisis para una nueva sociedad rusa, lo que afectó a la arquitectura sin perspectivas ideológicas, sumida en el letargo y con propuestas poco relevantes. Diferente fue lo expresado y realizado por la fotografía, la literatura, el cine, la pintura y la música, que se enriquecieron ideológicamente de la protesta social, entre condiciones favorables o contrarias, sea de los valores pro-occidentales o soviéticos.

Estas condiciones se revertirán con las reformas impuestas por Vladimir Putin ${ }^{10}$ amparado en la subida de las materias primas rusas, el desarrollo industrial, el libre mercado, la privatización y la inserción a los procesos de globalización. A la par, apostó por la difusión del nacionalismo ferviente, a reinstaurar el sentimiento a la gran madre patria rusa mediante el valor de los símbolos, fechas y héroes nacionales, la repotenciación de las fuerzas armadas, la difusión de tradiciones culturales y el restablecimiento de la religión ortodoxa. Todo esto, unido al crecimiento de la economía familiar, la responsabilidad del Estado en asumir problemáticas sociales $\mathrm{y}$ una mejor distribución de la riqueza, para situar al país otra vez como potencia mundial.

Esta apertura permitiría, en la arquitectura, actualizar el debate y el intercambio de ideas con propuestas de occidente que se reafirmarían en las principales obras públicas y privadas. Esto se logró a través de concursos internacionales con intervenciones de prestigiosas oficinas de arquitectos extranjeros como UN STUDIO, MVRDV o Rem Koolhaas (figuras 8 y 9) y la incorporación de arquitectos rusos al ámbito mundial, con gran suceso, como Alexander Brodsky, Yuri Grigoryan, Serguei Choban o Nicolas Pereslegin. De igual manera, el intercambio de ideas se ha conseguido a través de congresos internacionales, como el influyente Foro Urbano de 


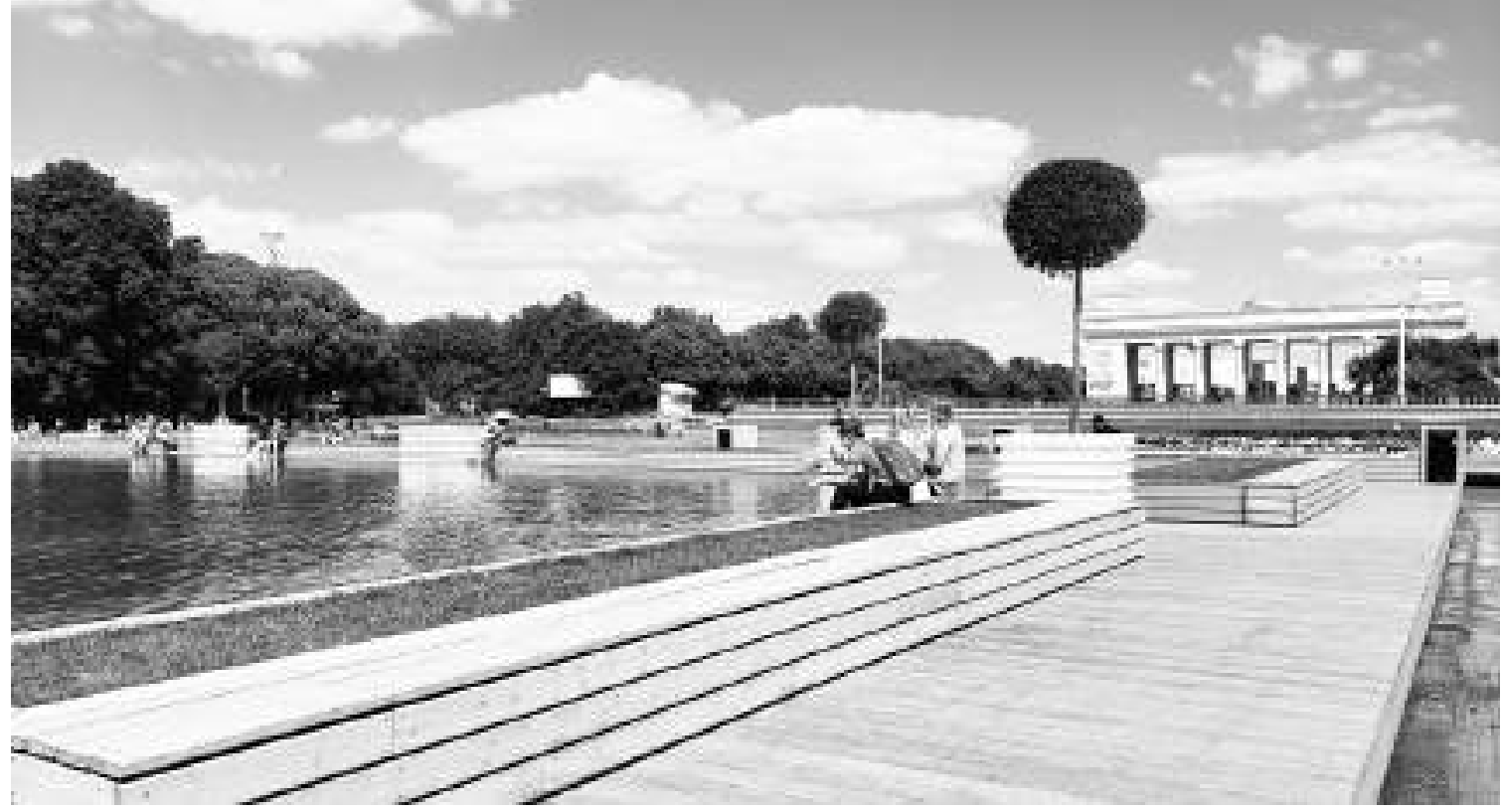

Figura 8. Parque Maxim Gorki, diseño paisajístico original del arquitecto constructivista Konstantin Melnikov. Inaugurado en 1928. Reformado en 2012. Foto: C. Castañeda, 2018.

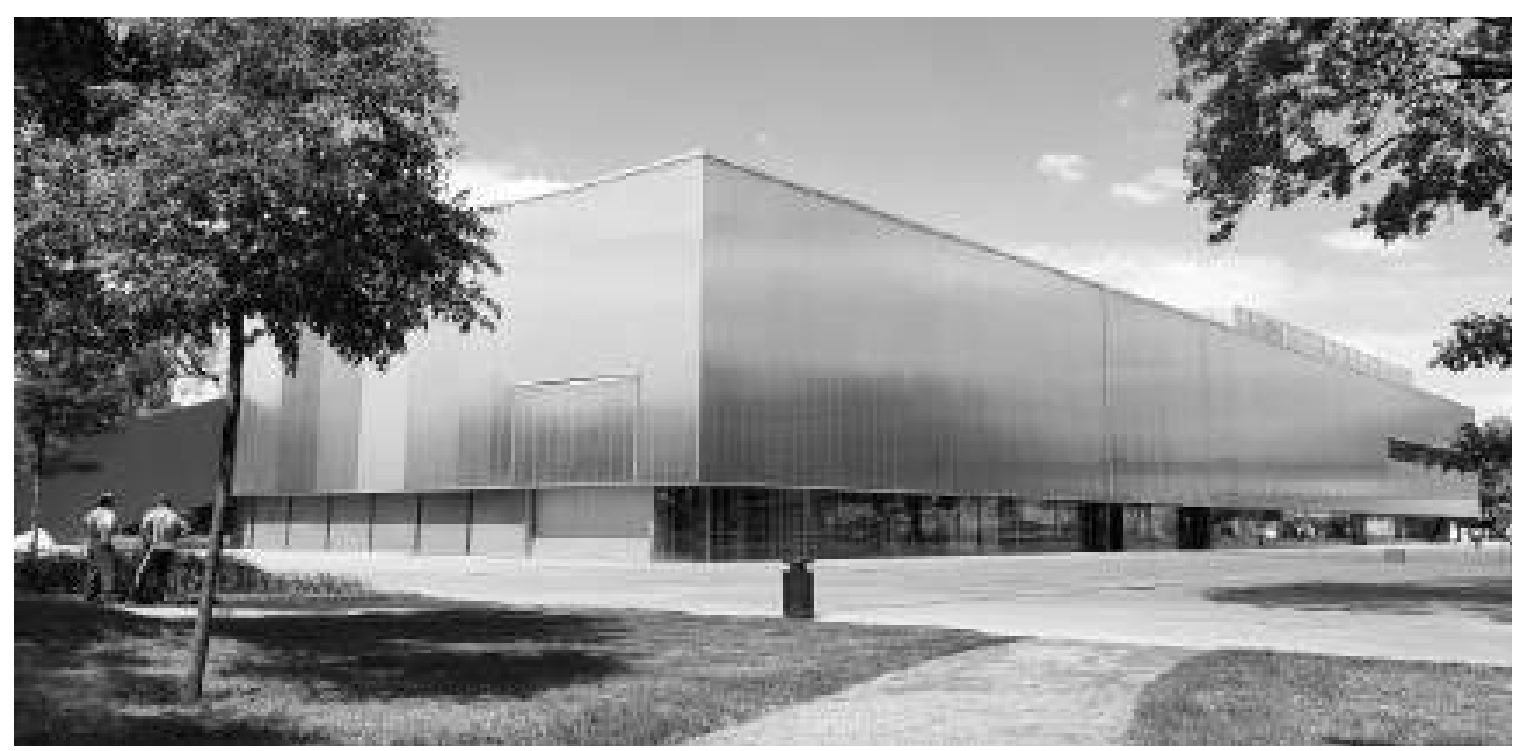

Figura 9. Museo de Arte Contemporáneo de Moscú, Garage, es una obra de reconstrucción y ampliación de Rem Koolhaas, OMA, 2015. Ubicado en el parque Maxim Gorki. Foto: C. Castañeda, 2018.

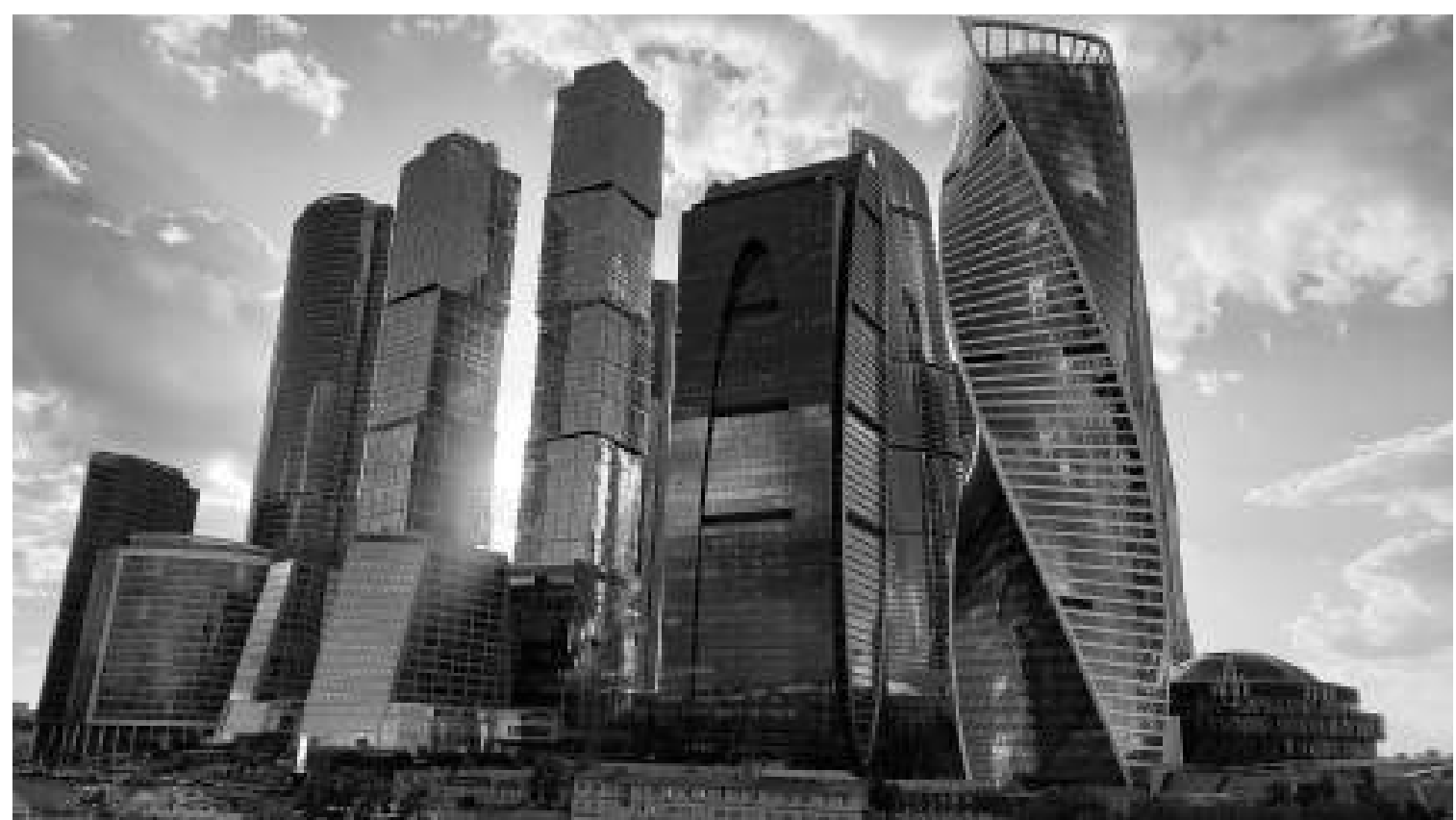

Figura 10. Centro Internacional de Negocios de Moscú. Foto: C. Castañeda, 2018. 
Moscú, auspiciado por el gobierno ruso y que se celebra anualmente desde el 2011.

La arquitectura en Rusia también se ha desarrollado a partir de la injerencia del Estado, haciendo atractiva la inversión extranjera y nacional con nuevas oportunidades, mediante la realización de foros económicos, culturales y de innovación tecnológica. También, promoviendo megaproyectos como los centros financieros internacionales en Moscú y San Petersburgo. En menos de una década Rusia ha logrado ostentar 7 de los 10 edificios más altos de Europa, centrando su imagen desde la globalización, con las características genéricas que se extienden en todo el mundo. (Figura 10)

David Moriente (2010), en su crítica a la ciudad genérica de Rem Koolhaas, indicará: "las ciudades actuales se están convirtiendo en réplicas de un mismo modelo urbano y extensiones indefinidas de poblaciones deshumanizadas sin identidad..." (p. 146) Señala, además, que esta denominada metamorfosis de la arquitectura y la ciudad ha transformado al ciudadano mediante "módulos contenedores de personas o, dicho de otro modo, en espacios para producir sujetos inconscientes de su propio confinamiento." (p. 147)

El Estado, asimismo, ha manifestado un inusual y marcado interés en eventos deportivos de carácter mundial, lo que permite dar a conocer el resurgir ruso y que, a similitud de la nueva arquitectura de los centros de negocios, ha fomentado el interés por mostrar una imagen de país globalizado. Previo a la Copa Mundial de fútbol FIFA 2018 se realizaron, entre otros, el campeonato Mundial de Atletismo en Moscú (2013), los Juegos Olímpicos de Invierno en Sochi (2014) (figuras 11 - 20) y el Campeonato Mundial de Natación en Kazán (2015), todos ellos con un impacto mundial comparable solo con los Juegos Olímpicos de Moscú de 1980.

Podemos decir que la expresión de la arquitectura realizada en Rusia ha virado bruscamente hacia la internacionalización." Expresiones contemporáneas que, como señalaría Montaner (2011) se darían en la arquitectura a partir de miradas distintas, plurales y complejas intentando expandirse sin límites. El recurso al instrumento abstracto, complejo y versátil de los diagramas, la necesidad de incorporar la arquitectura a la sostenibilidad y los reequilibrios ecológicos, el incorporar el paisaje como referencia de la arquitectura, el urbanismo, la geografía, la literatura y el arte, así como el replanteo de la arquitectura desde el paradigma del reciclaje constituyen, todas ellas, miradas encontradas. De hecho, existe una concordancia con lo señalado por Roberto Fernández en sus lógicas proyectuales (2000) donde indica la importancia de las tres grandes formas del pensamiento reflejadas en el arte, la ciencia y la filosofía. En este aspecto sería más importante direccionar las diferencias, no solo como objeto sino más bien como formas plurales de intervención y de mirar el problema, como también señala Hernández (2010) en los nuevos rumbos de la arquitectura.

Más allá del vacío que se generó con la intromisión de los gobiernos en la época soviética y de algún modo en la era Putin, a través de inducir la imagen arquitectónica de monumentalidad y expresión globalizada como política de Estado, lo cierto es que se ha priorizado en las edificaciones más representativas una contemporaneidad que se sostiene sobre la influencia del capitalismo, con preferencia por los modos abstractos y genéricos que incurren hacia propuestas de no lugar. ${ }^{12}$ Otras privilegian la iconicidad del objeto, como parte de una serie de relaciones que se iniciaron en Europa y Estados Unidos entre el arte, el cine y la arquitectura, desde la década de 1970, para promover conceptos y significados de lo arquitectónico. ${ }^{13}$ (Moriente, 2010)

Esto se ha plasmado en los lugares de tránsito (aeropuertos, estaciones de tren, estaciones de metro, carreteras) y lugares de consumo masivo (centros comerciales) evidenciando su neutralidad y el uso de materiales donde predominan el acero, el vidrio y la luminosidad excesiva, así como una marcada presencia de lo tecnológico, que hace posible el funcionamiento del edificio. (Figura 21) Una imagen que también ha incurrido en lo ornamental, que se desarrolla en envolventes formales, permitiéndose licencias conceptuales poco ingeniosas que promueven la individualidad del arquitecto como ícono. "Una cultura arquitectónica que solo valora la novedad, la invención y la creatividad individual" (Davies, 2011, p. 36)

Fruto de esta mutilación (el no lugar genérico, característico de la globalización) es la idea de que la única manera de combatir a los no-lugares es ocuparlo todo con lugares, llenando el mundo 
de significados e íconos, ahogando a las ciudades con los frutos de la memoria en un horror vacui oprimente y falaz. La paradoja resultante es clara: el repetido, hipertrofiado lugar se convierte en algo sin cualificar, es decir, en una cosa genérica más. El espacio genérico y el lugar genérico, el no-lugar y el lugar acaban, de un modo paradójico, fundidos en una deprimente identidad. (Prieto, 2011, p. 99)

Lo particular del lugar en la arquitectura global queda desterrada bajo las condiciones de los contenedores ${ }^{14}$ que conforman un sitio en sí mismo, obviando situaciones climáticas y geográficas que la tecnología sustituye. Esto propicia una creciente serie de monumentales edificaciones que rompen con aquellas idealizaciones de la nostalgia post soviética, las que buscan en la arquitectura un modo de pertenencia y de reconocimiento, que se han visto limitadas a intentos escuetos y poco cavilados de elementos simbólicos y referenciales donde el nacionalismo apunta hacia la monumentalidad, las innovaciones tecnológicas, el efectismo nocturno y todo aquello que sea expresión de poder institucional.

(... ) llegar a una presencia global, es decir, una omnipresencia conseguida a través de la repetición y difusión universal de sus imágenes más características, íconos de fácil consumo que, una vez replicados, son distribuidos por los omnímodos canales virtuales, multiplicándose sin descanso como si albergasen en su interior un juego de espejos enfrentados. Para que el efecto clonador sea efectivo, es necesario recurrir a aquellas imágenes (el rascacielos, la pirámide, las luces efectistas) cuyo efecto epatante esté garantizado. (Prieto, 2011, p. 48)

Estas condiciones, sin embargo, también han promovido algunas muestras de evadir lo globalizado para retornar a lo particular y recurrir a una serie de tendencias simbólicas recargadas, rescatadas de lo eclesiástico ortodoxo, de las condiciones climáticas y, sobre todo, en la expresiva saturación de colores y formas del arte y la arquitectura de influencia islámica, ${ }^{15}$ exclusiva mezcla de filigrana que ha conseguido construir una imagen con cierta identidad. (Figura 22) En todo caso, estos modos de realización no están siendo tomados en cuenta o recogidos en la arquitectura rusa actual, con modos esquivos a la continuidad evolutiva, en su inserción globalizada. (Figura 23)

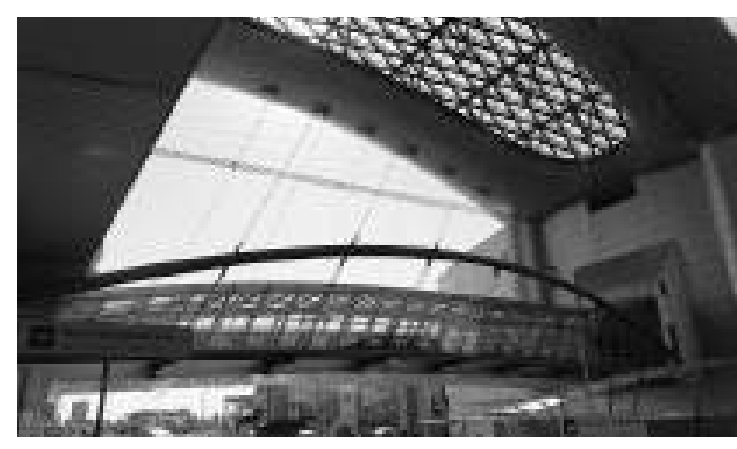

Figura 21. Explanada de ingreso al Aeropuerto Internacional de Moscú - Sheremétievo. Foto: C. Castañeda, 2018.

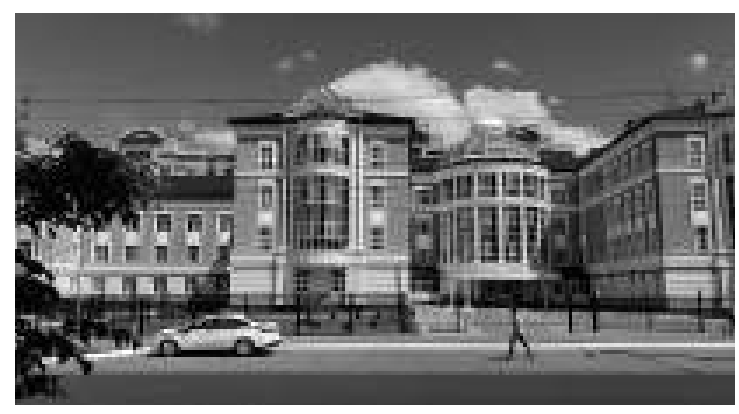

Figura 22. Arquitectura pública contemporánea en Saransk, como modos de enfrentar lo globalizado. Foto: C. Castañeda, 2018.

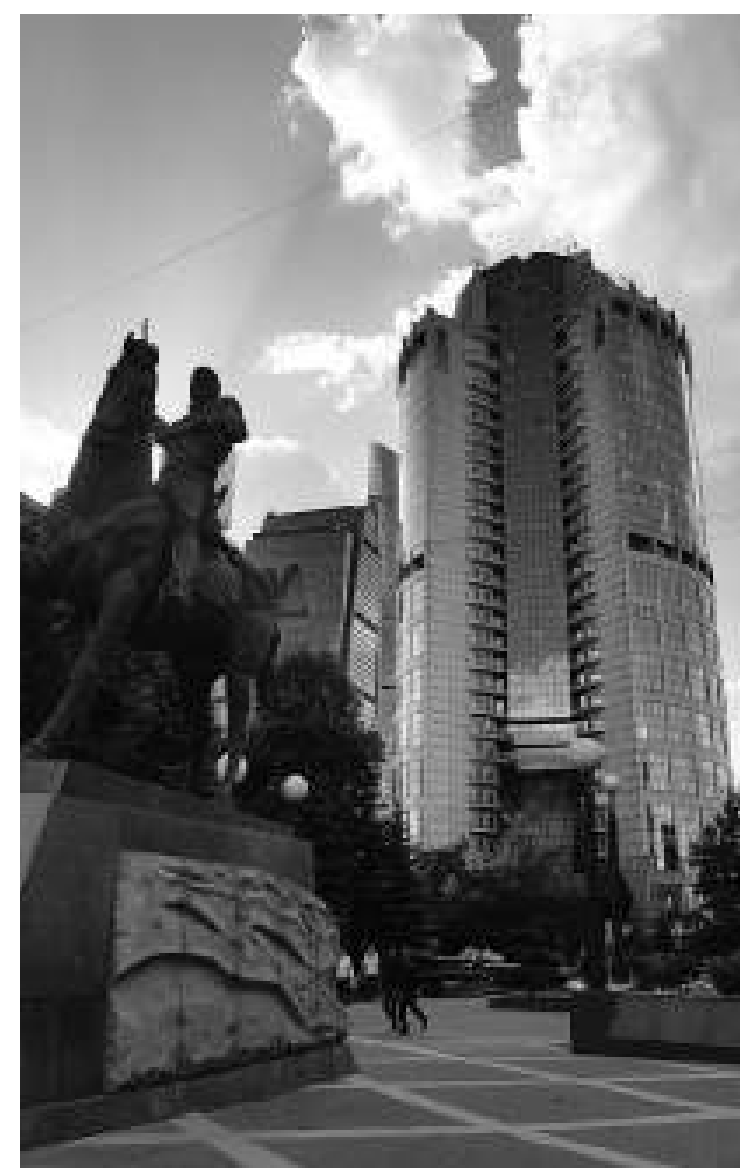

Figura 23. Arquitectura contemporánea en Moscú, con mayor búsqueda de ornamento e identidad. Foto: C. Castañeda, 2018. 


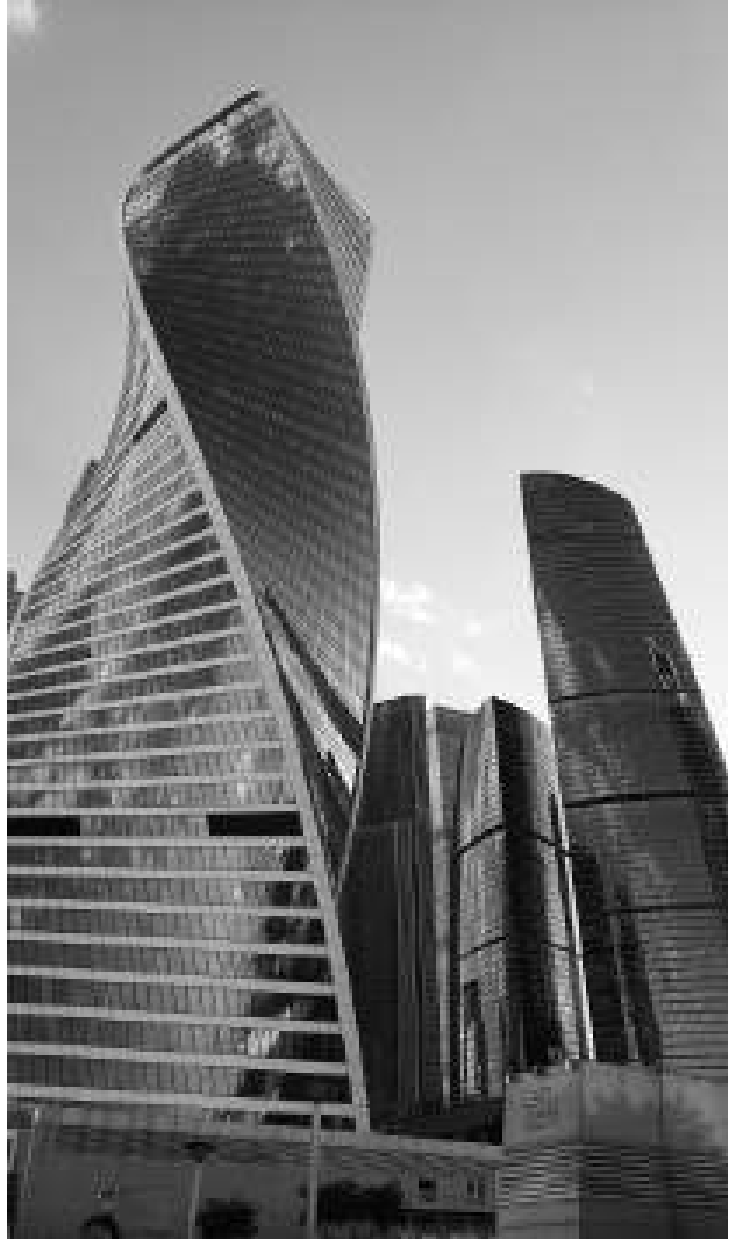

Figura 24. En primer plano, edificio Evolution Tower (2014) diseñado por la firma inglesa RMJM, con la participación del artista escocés Karen Forbes y el arquitecto ruso Philipp Nikandrov. El retorcimiento en forma de hélice se logra con plantas que totalizan un giro de 156 grados. Foto: C. Castañeda, 2018.

La arquitectura contemporánea globalizada, así como abandona el lugar fenomenológi$\mathrm{co}$, ha dejado de lado las condiciones funcionales, la racionalidad constructiva y estructural, la geometría euclidiana así como normas de composición tradicional, para dar paso a búsquedas de autoafirmación y autosuficiencia de lo formal. ${ }^{16}$ Se proponen objetos no solamente escultóricos sino icónicos, donde la función variable y mutable del contenedor ha sido lograda a partir del uso del ordenador y nuevas tecnologías constructivas. (Figura 24) Kenneth Frampton (2007) sitúa esta arquitectura desde las relaciones con lo orgánico, la naturaleza, las cualidades de las células microscópicas para crear respuestas a diversas condiciones o desde propiedades de termodinámicas 0 mecánicas. (Davies, 2011, p. 121; Prieto, 2011, p. 72; Montaner, 2011; Español, 2001) “Una nueva arquitectura sin entorno, sin medio urbano o rural, más bien el intento es marcar un entorno con la misma obra y definir un nuevo tipo de paisaje, el lugar lo marcará la nueva obra." (Bernarderle, 2009, p. 225)

En este panorama arquitectónico se suma la tendencia a la sostenibilidad, enfatizando la eficiencia energética, el cuidado de la atmósfera, el reciclaje, el uso de materiales menos contaminantes, la gestión de recursos, el cuidado del agua, la calidad ambiental, entre otros, que salvo casos logrados con creatividad y oficio terminan manifestándose como una moda, lo que también altera y tergiversa el concepto arquitectónico desde indicadores que derivan hacia la valoración técnica de la eficiencia de elementos servidores.

Montaner (2011, p. 174) desarrolló ideas sobre el ahorro energético, el reciclaje y lo ecológico, tres cuestiones claves para una auténtico análisis cualitativo de la arquitectura.

En primer lugar, no tiene sentido una arquitectura pretendidamente ecológica que elimine preexistencias ambientales y no se relacione con las tramas urbanas. La clave no está nunca en el mismo edificio, sino en sus adecuadas relaciones con el entorno, con los estratos de lo existente. En segundo lugar, cada cultura se encuentra en un estado diferente (...) En definitiva no hay modelos para imponer de un contexto a otro: cada lugar debe tener la posibilidad de generar sus propias soluciones, relacionadas con la cultura, su medio (...) El imperialismo industrial convierte incluso los productos verdes en otra gama de productos multinacionales que unos contextos imponen a otros. Y, en tercer lugar, el paulatino aumento de las cualidades ambientales de las ciudades va aparejado con la mejora de las zonas comunitarias.

Todas estas tendencias están dispersas en una buena parte de la arquitectura contemporánea rusa. Eduardo Prieto (2011) nos habla de ciudades encarceladas por lo digital, las ciudades in vitro (Montaner, 2011) o, como señala David Moriente (2010): “Las particularidades que probablemente asumirán esas ciudades-monstruo y que se encuentran actualmente en un estado embrionario se pueden reunir en tres: gigantismo, eclecticismo y estratificación tecnológica, que se unirán a los efectos de una preocupante y descontrolada autorreplicación.” (p. 286) 
A pesar que en la arquitectura rusa se han manifestado lógicas en el sentido que Roberto Fernández (2000) establece, como contextualista, tipologista y estructuralista, estas no han sido evidenciadas en este artículo, en la medida que no son aquellas las que la arquitectura rusa ha mostrado al mundo como sinónimo de poder y contemporaneidad, sino otras que recurren a lo comunicacional, lo tecnológico y formalista, mayormente ligado al consumo globalizado. Intentaremos verificarlo en las propuestas realizadas para el Mundial de fútbol Rusia 2018.

\section{RUSIA 2018. La expectativa arquitectónica desde cuatro estadios}

La importancia que se da al deporte en Rusia es un rasgo que continúa el legado soviético de hacer de la práctica deportiva una forma de vida, una necesidad y una tradición inculcada desde la niñez. Para ello, el gobierno ruso destina uno de los presupuestos más elevados, respecto a países de primer mundo, para la práctica amateur y de élite, lo que finalmente tiene sus logros en los distintos cuadros medalleros de los juegos olímpicos, de invierno o campeonatos mundiales en deportes como el ajedrez, la gimnasia, el patinaje artístico, el jockey sobre hielo o el atletismo.

El fútbol, sin embargo, no se considera el deporte más popular en la sociedad rusa, tampoco ha permitido generar importantes éxitos deportivos ${ }^{17}$ y durante toda la era soviética solo se habían construido cinco estadios mayores a 30000 espectadores, siendo el inclemente clima un factor importante para que esto suceda. En todo caso, a la FIFA le resulta poco relevante situaciones como esta para otorgar la sede de un mundial: de manera similar ya había ocurrido en USA 1994, Corea-Japón 2002 y Sudáfrica 2010, países donde el fútbol no concita mayor interés.

Estas condiciones, sin embargo, no fueron impedimento para postular y ser sede de la copa del mundo: un evento de evidente interés político, que pudiera seguir mostrando al mundo las capacidades de Rusia y su creciente y rápido desarrollo desde su apertura al sistema capitalista. "La administración Putin, siguiendo las huellas de la Unión Soviética, está buscando demostrar la superioridad de su pueblo a través de las campañas deportivas... No ha escatimado en el empleo de todo recur- so para obtener resultados positivos." (Rivas, 2018, p. 22) Este evento también permitiría al mundo ingresar y conocer el entorno político, social, cultural, artístico y, por supuesto, el urbano-arquitectónico, de sus edificios, espacios públicos y paisaje, en especial, lo que dejarán como legado los estadios de las diferentes sedes, como referentes tecnológicos a futuro.

A la arquitectura de los estadios históricamente se le ha otorgado pequeños espacios en los libros y revistas de la especialidad, aunque en algunos casos hayan podido convertirse en referente y trascender a su propia tipología deportiva. Ejemplos importantes podemos apreciar en la escultural y desafiante propuesta brutalista de Kenzo Tange para el Gimnasio Nacional de Yoyogi para las Olimpiadas de Tokio (1962); la magistral tenso estructura de Frei Otto para el Olympiastadion Munich para los Juegos Olímpicos de Munich (1972) y el Mundial de fútbol de Alemania (1974); la envolvente escultórica de una sola pieza del Domo de Sapporo de Hiroshi Hara para el Mundial de fútbol Corea-Japón (2002); la impresionante membrana lumínica para el estadio Allianz Arena de Herzog \& de Meuron para el Mundial de fútbol de Alemania (2006) y el icónico estadio denominado "nido de pájaro", también de Herzog \& de Meuron, para las Olimpiadas de Beijing (2008).

En este sentido, el Mundial de Rusia 2018 despertaba también un gran interés por saber qué es lo que se intentaba distinguir o innovar en la arquitectura deportiva contemporánea. De inicio habría que indicar que, de las doce sedes, diez fueron proyectadas por firmas extranjeras, similar a lo sucedido en los mundiales de Sudáfrica (2010) y Brasil (2014). En todos los casos, las firmas extranjeras y locales priorizaron la envolvente, la imagen, lo monumental, las normativas de sostenibilidad y lo tecnológico, por sobre condiciones del lugar, la cultura o tradiciones particulares. A esto se sumaría la preocupación sobre el costo-beneficio y la viabilidad a futuro de los estadios, destinados a funcionar durante el periodo del mundial sin poder luego recuperar, en muchos casos, el gasto público. Esto último fue previsto en Rusia a partir de preparar, para cuatro estadios, estructuras desmontables que una vez culminado el campeonato mundial de fútbol pudieron reducir sustancialmente su capacidad. 
Año 26, No 34, enero-diciembre de 2019
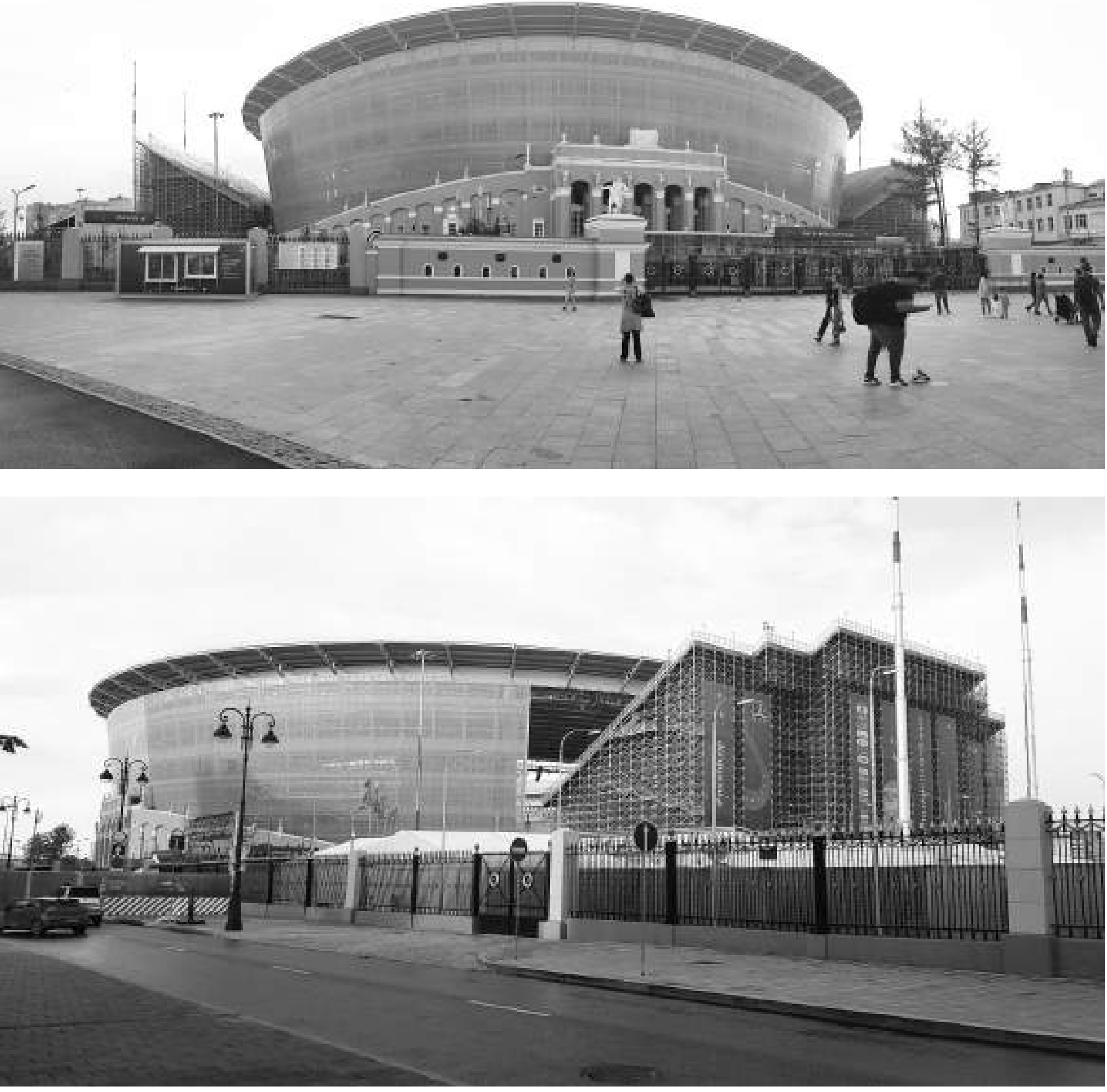

Figuras 25 y 26. Ekaterimburgo Arena. Diseño: Projects Institute (PI) Arena. Reconstrucción: 2018. Vistas del nuevo estadio, con partes de la antigua fachada. Fotos: Adolfo Morey, 2018 
De las propuestas nos centraremos en revisar las cuatro sedes visitadas durante el mundial. Estas son: el Spartak Stadium de Moscú, inaugurado el 2014 con capacidad para 45360 espectadores, diseño de la firma inglesa Dexter Moren Associates; el Ekaterimburgo Arena en la ciudad de Ekaterimburgo, reconstruido el 2018 con capacidad de 35696 espectadores y reducido a 23000 después del mundial, diseño de la firma rusa Projects Institute (PI) Arena; el Mordovia Arena de Saransk, inaugurado el 2018 con capacidad de 44442 espectadores y reducido a 28000 al finalizar el evento, fue diseñado por el arquitecto alemán Tim Hupe; por último, el Olímpico Fisht de Sochi, inaugurado el 2013 con capacidad para 48000 espectadores, diseñado por la firma estadounidense Populous.

Sobre las firmas encargadas se observa que Populous muestra mayor experiencia en proyectos de arquitectura deportiva, con grandes obras de carácter icónico y marcado contraste con el contexto urbano. La firma rusa PI Arena intenta mostrar un lado más conceptual, filosófico y escultural en sus propuestas, con cierta experiencia en proyectos deportivos. En el caso de Dexter Moren Associates y Tim Hupe, la obra de ambas oficinas es distante a los modos escultóricos y efectistas, manteniendo una arquitectura sobria que se decanta por una elaborada revisión del entorno urbano, buscando la sencillez, la geometría clara y una escala pertinente, siendo ambas oficinas las de menor experiencia en el rubro de arquitectura deportiva. ${ }^{19}$

La propuesta de PI Arena en Ekaterimburgo conserva las fachadas del antiguo estadio construido en 1935 (considerado patrimonio cultural) teniendo la nueva intervención un retiro volumétrico con materiales de imagen neutra que contrasta con lo existente, habiendo entre ambas fachadas un interfaz espacial. "Su fachada histórica se ha mantenido inalterada, respetando así su condición de legado arquitectónico. En la construcción de las gradas se emplearon abundantes elementos arquitectónicos y decorativos propios del neoclasicismo soviético, junto con artes decorativas..." (FIFA, 2019) Así mismo, ante el requerimiento de reducir posteriormente su capacidad, propone una solución novedosa y polémica a través de una tribuna fuera del volumen del estadio. En este sentido, se hace evidente una solución claramente for- mal que hace alusión a condiciones de uso. La propuesta escultórica de la firma se percibe rápidamente en la solución arquitectónica, dejando las tribunas expuestas a las condiciones extremas del clima. (Figuras 25 y 26 )

La propuesta de Populous en Sochi, sin perder su carácter globalizado, ha logrado que contenga algunas características del lugar; la primera de ellas, aunque simplista, conceptualiza las dos tribunas principales como montes nevados del Cáucaso o la forma envolvente de una concha marina del Mar Negro. También hace referencia a los huevos de Fabergé, obras maestras de la joyería creadas para los zares de Rusia y algunos miembros de la nobleza y la burguesía, hacia fines del siglo XIX. (Figuras 27 y 28)

En este estadio se manifiesta un mayor logro en los recorridos deambulatorios, un espacio que se vuelve externo y permite vistas a los paisajes circundantes. (Figura 29) Esto es significativo, porque de algún modo estas licencias de apertura al exterior solo se pueden dar en Sochi, donde las temperaturas no son extremas como las ciudades ubicadas hacia el centro y norte del país. ${ }^{20}$ De igual modo la propuesta del Fisht es la única que permite una propuesta de espacio público al formar parte de la villa olímpica abierta al público, permitiendo actividades sociales y culturales no realizadas en los otros tres estadios.

Finalmente, las propuestas de Tim Hupe en Saransk y de Dexter Moren Associates en Moscú difieren sustancialmente de su actividad proyectual y la búsqueda continua de contextualizar sus propuestas. Eso no se logra mostrar en los estadios rusos, insinuándose en ambos una débil conceptualización sobre el color de la envolvente, atrapados en un efecto cromático. En este sentido, la envolvente del estadio de Spartak en Moscú mostrará los colores del equipo local (figura 30) y la del Mordovia Arena en Saransk los colores de la artesanía regional (figura 31).

A pesar de algunas condiciones de aparente particularidad, no se evidencian otras singularidades en los proyectos analizados. Los cuatro estadios señalados encaran el discurso arquitectónico desde la sujeción a condiciones predefinidas del mundo globalizado. A pesar que la trascendencia histórica de los estadios siempre se ha mostrado desde 
la innovación tecnológica y constructiva, lo cierto es que estos estadios han optado por sostenerse desde su condición de objetos, pero sin un aporte que permita nuevos caminos más trascendentes para lo deportivo en los próximos años; más aún cuando la escala urbana y peatonal, la ciudad, lo climático y el espacio público han pasado a segundo plano.

Los estadios creados como objetos terminan siendo contenedores que intentan crear efectos visuales: en lo formal, en algún aspecto de la funcionalidad, en la racionalidad estructural o tectónica. ${ }^{21}$ La forma por la forma se basa y sustenta en las dos condiciones más importantes de la arquitectura globalizada como es la aplicación de las nuevas tecnologías y el uso de herramientas de software de diseño para consolidar las envolventes tridimensionales de dichos contenedores en base a cubiertas o pieles que se sitúan bajo estructuras aleatorias, para lograr un impacto visual principalmente nocturno. (Figura 32)

Los resultados en este tipo de encargos son similares, diferenciándose únicamente desde la opción del material, la retícula y el color. Según los conceptos de Hernández (2011), estas envolventes tecnológicas son aportes en la arquitectura cuando producen orden urbano, a partir de la responsabilidad ambiental y social. Esto no necesariamente contradice otras características vinculadas a la velocidad, dinamicidad, flexibilidad, inestabilidad, turbulencia y mutación de formas, entre otras, lo que permite diversas maneras de mirar el problema, pero que no se logran observar en los estadios, salvo lo ya mencionado sobre el estadio en Sochi, del que se valora su vocación pública.

En la arquitectura de los cuatro estadios encontramos un cierto horror al vacío, incorporando el ornamento de manera simplista en el Mordovia Arena y el Spartak Stadium, un exceso de monumentalidad en las vigas de cubierta, como ocurre explícitamente en Sochi (figuras 33 y 34) y en menor medida en Spartak (figura 35), así como la aplastante escala en la que incurre el Ekaterimburgo Arena, tanto con la fachada antigua que se conservó como en su relación con la ciudad. (Figura 36)

Más allá de la imagen exterior, otras condiciones son importante en las propuestas arquitectónicas, como son las visuales desde las tribunas hacia el campo de juego, los accesos, las escaleras y pasadizos, la ubicación de los espacios destinados a la asistencia del público: todo lo que implica la realización del encuentro, sobre lo que se tienen normas pre-establecidas. En este sentido se cumplen

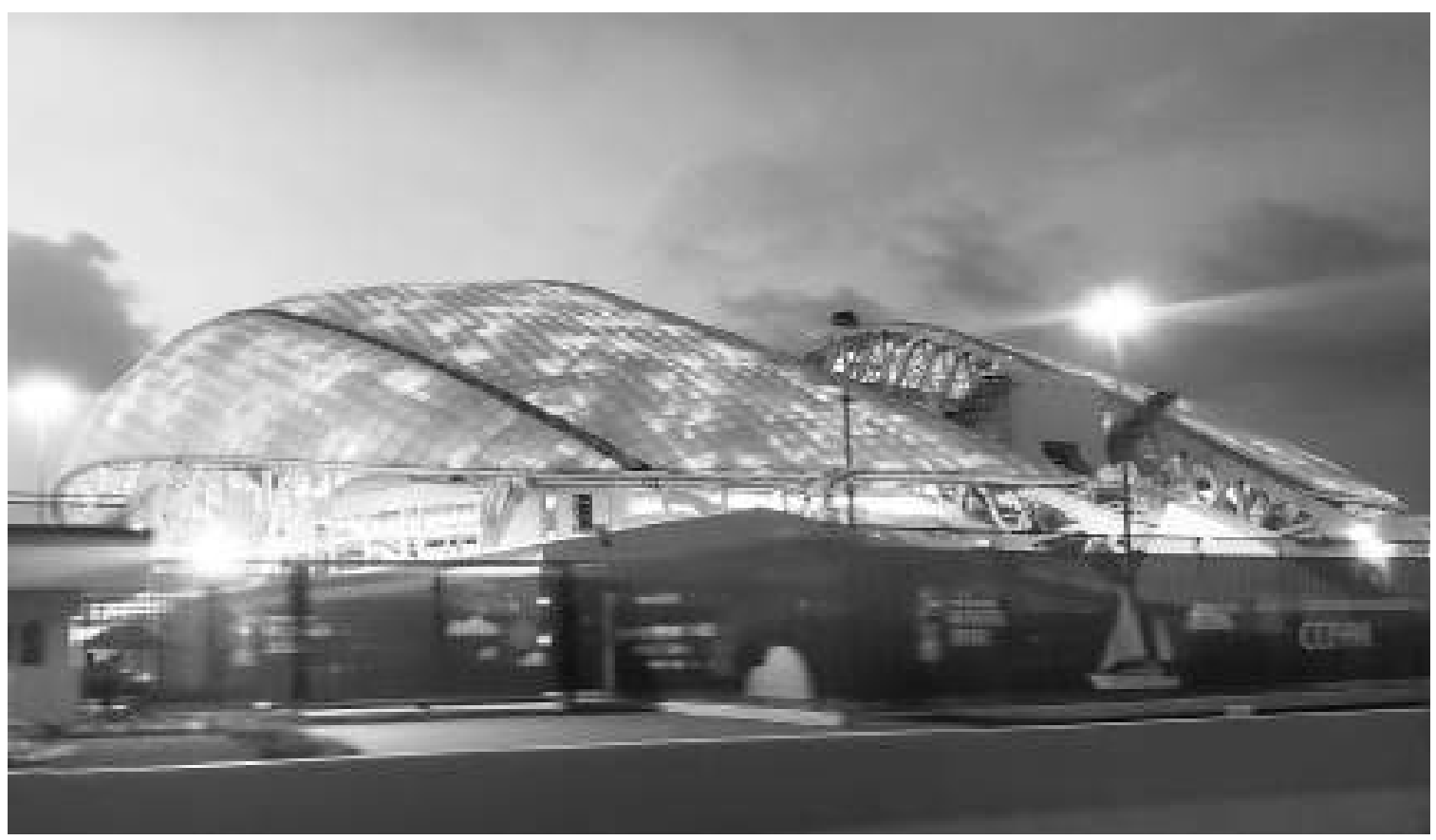

Figura 32. Estadio de Sochi. Vista nocturna, con la propuesta de iluminación alrededor de las dos envolventes. Foto: C. Castañeda, 2018. 


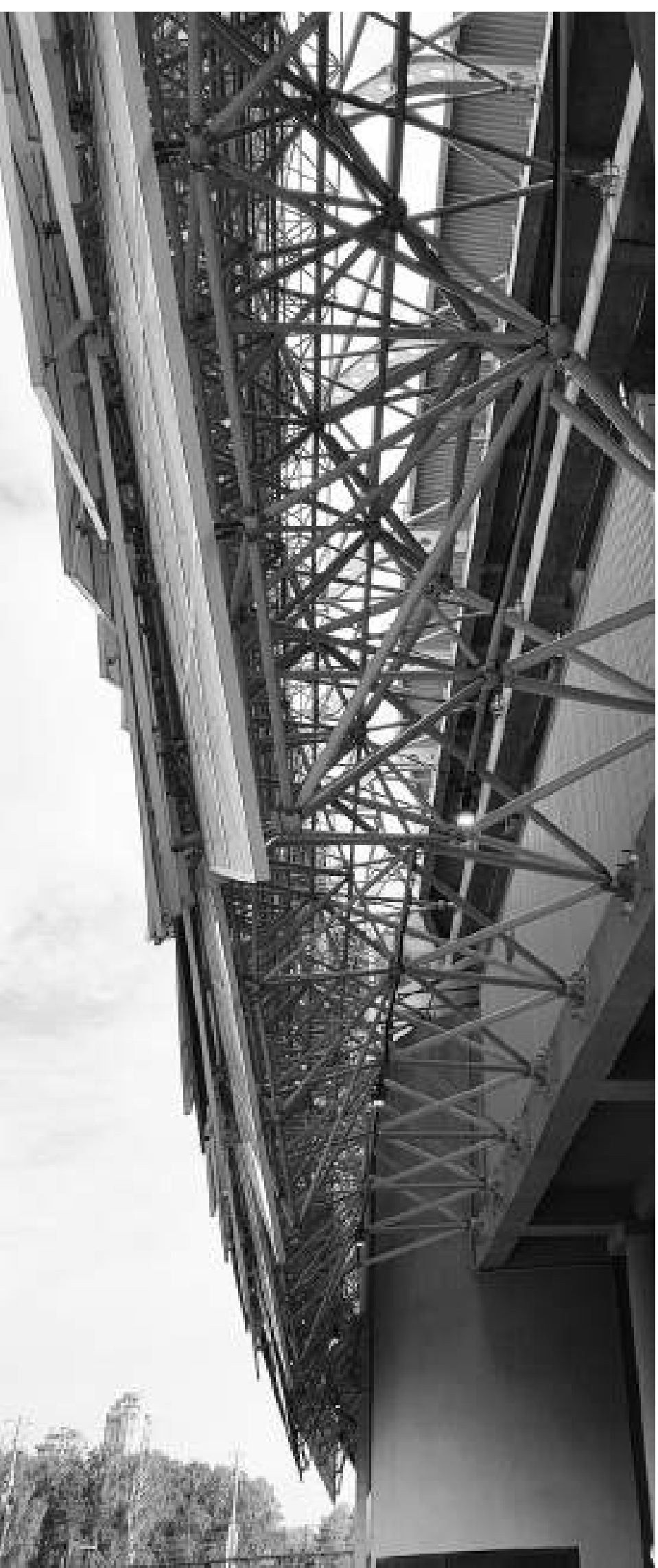

Figura 35. Spartak Stadium de Moscú. Vista de la estructura metálica que soporta la envolvente diagonal. Foto: C. Castañeda, 2018. con las expectativas señaladas y la particularidad va dirigida, una vez más, a la exposición y disposición del color en los asientos para dotar al estadio de una imagen lúdica, dentro del marco de entretenimiento esperado y que es recurrente desde mediados de la década de $1980 .{ }^{22}$ De igual modo los estadios del Mundial Rusia 2018 han privilegiado la práctica del fútbol y por lo tanto una mayor cercanía de las tribunas al campo de juego, aproximando el público al espectáculo. (Figura 37) Este cambio se ha dado desde el Mundial Alemania 2006, por sobre la otrora visión de estadios que podían destinarse y utilizarse para diferentes actividades deportivas, para lo cual las tribunas se encontraban más alejadas del campo de juego. ${ }^{23}$

Al conjunto de relaciones entre el objeto arquitectónico y el individuo se suma la puesta en escena de lo digital y tecnológico, presente en la iluminación, los suministros, los calefactores, lo audio-visual y las normativas de impacto medioambiental, características de evaluación con las que cierta crítica intenta reemplazar lo artístico por lo técnico. Montaner (2011, p. 44) señala en este sentido la predominancia del contenedor neutro (transparente) que se valida con objetos, máquinas, imágenes y equipamiento, lo que configura interiores modificables y dinámicos, luz artificial que permite la desmaterialización de los límites espaciales y la fluidez, que repercute en la experiencia perceptiva y fenomenológica de los usuarios.

Todo esto no ocurre en los estadios señalados más que desde un efecto lumínico nocturno, ya previsible, que se viene dando en la arquitectura escenográfica de manera muy recurrente en las primeras décadas del siglo XXI. Condiciones tecnológicas que más allá del impacto visual exterior y auditivo al interior que puede causar en el espectador, resta la esencia espontánea del otrora ingreso de los jugadores al campo de juego, acompañada de auténticas manifestaciones de los asistentes. Esto ha sido reemplazado por la imposición de un show mediático, dirigido al entretenimiento consumista y publicitario, al cual cada vez más público se incorpora. El uso de recursos audio-visuales de comunicación, en alianza con la arquitectura, terminan por envolvernos una vez más en la civilización del espectáculo. ${ }^{24}$ 


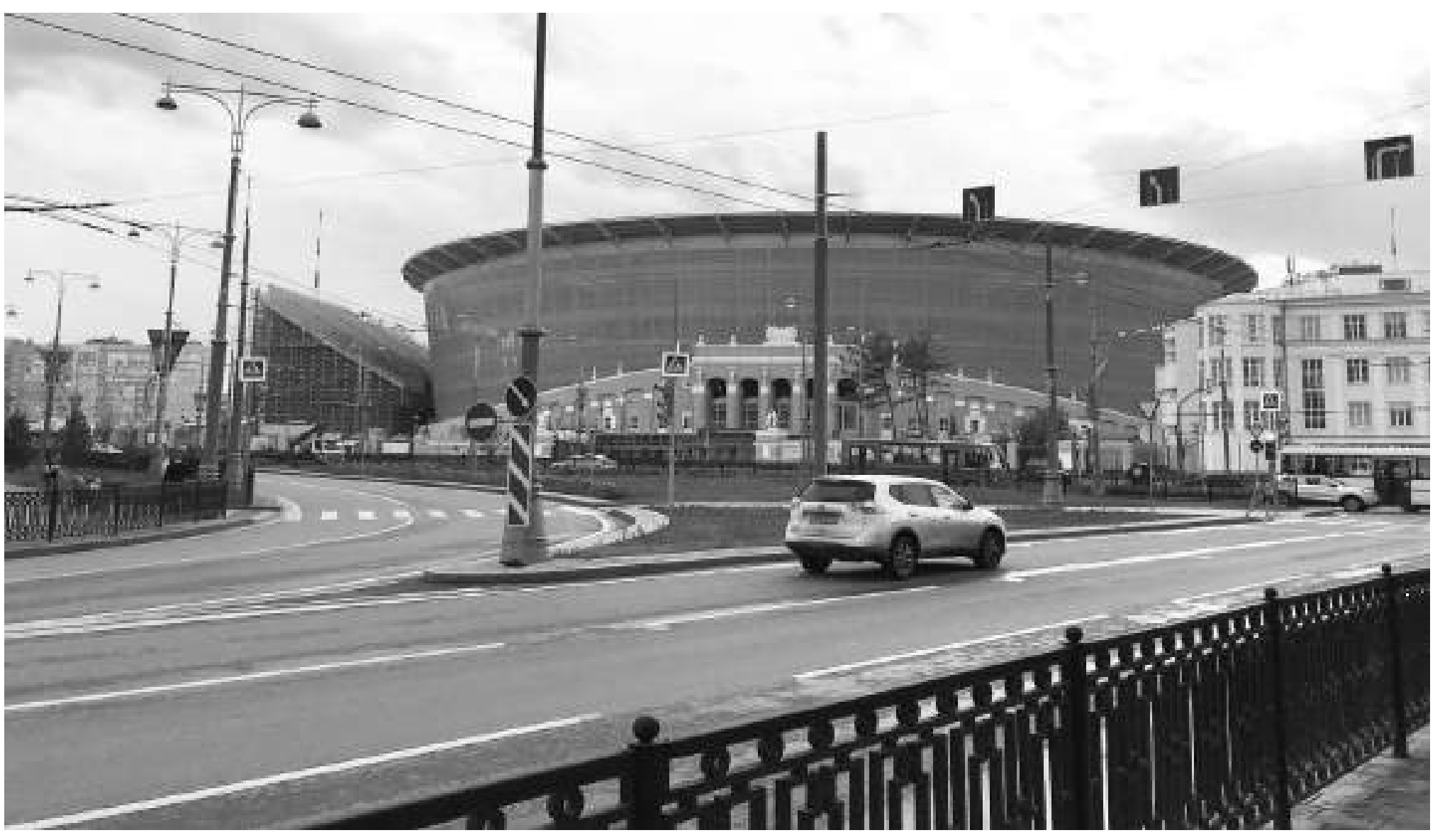

Figura 36. El Ekaterimburgo Arena, inserto en un entorno heterogéneo de formas y escalas dispersas, con algunas edificaciones históricas. El estadio se sitúa ajeno y extraño al lugar, a pesar de conservar partes de la antigua fachada. Foto: C. Castañeda, 2018.

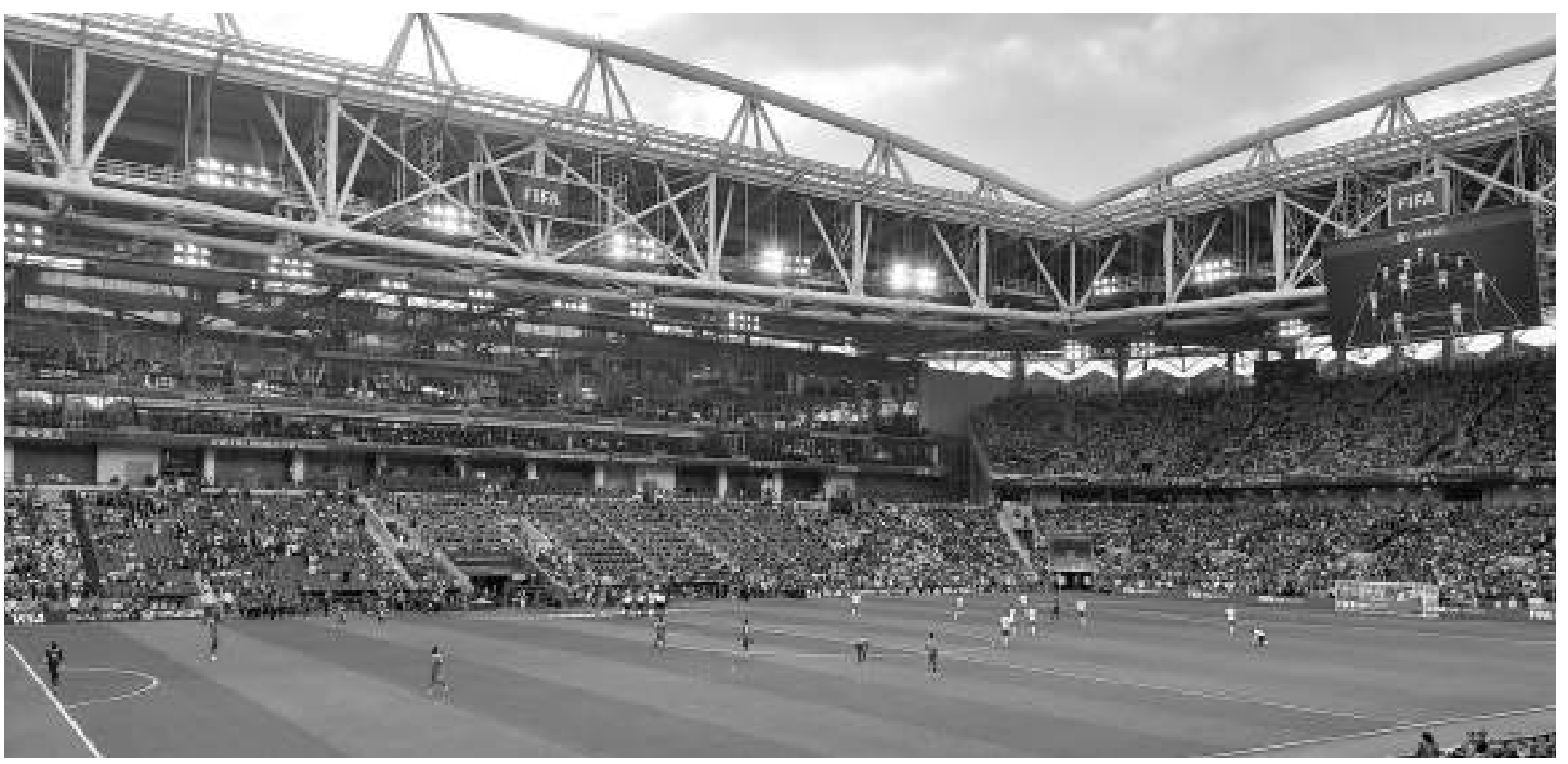

Figura 37. Spartak Stadium de Moscú. Instalaciones, sistema de comunicación y estructura metálica que confieren funcionamiento al estadio. Foto: C. Castañeda, Mundial Rusia 2018. 


\section{Notas}

1 Como ejemplo de interferencia política en el campo deportivo, mencionamos los deseos impuestos por Benito Mussolini para que la selección de fútbol italiana represente ideales del fascismo, así como una serie de situaciones extradeportivas para que la "Nazionale" se adjudique los títulos en los mundiales de 1934 y 1938. También, la alteración de resultados por parte de Adolf Hitler durante los Juegos Olímpicos de Berlín 1936, así como el uso de los juegos para promover el nacionalsocialismo. Por su parte, el uso del Mundial Argentina 78 por parte del dictador Jorge Videla para distraer y ocultar crímenes de Estado. Todos ellos, entre otros casos, son ejemplos de relaciones entre lo político-militar y el fútbol.

Sobre el Perú, el internacionalista Farid Kahhat (2018) indicaría: "el velasquismo hizo de la promoción del deporte, en general, y del fútbol, en particular, una cuestión de Estado, al punto de que no solo se respaldaba a la selección masculina de fútbol, sino que incluso las distintas instituciones castrenses respaldaban a equipos particulares..."

2 El Mundial de fútbol FIFA 2018 realizado en Rusia se desarrolló en 12 estadios de 11 sedes que, salvo Ekaterimburgo ubicado en el lado asiático, todas las demás pertenecen al lado europeo. Las sedes elegidas fueron: Moscú (Luzhniki Stadium, Spartak Stadium), San Petersburgo (San Petersburgo Stadium), Kaliningrado (Kaliningrado Stadium), Nizhni Novgorod (Nizhni Novgorod Stadium), Volgogrado (Volgogrado Arena), Ekaterimburgo (Ekaterimburgo Arena), Sochi (Fisht Stadium), Rostov del Don (Rostov Arena), Saransk (Mordovia Arena), Samara (Samara Arena) y Kazan (Kazan Arena).

3 Roberto Fernández (2000) propone que la arquitectura contemporánea tiene una serie de conductas proyectuales a las cuales denomina "lógicas proyectuales": tipologista, estructuralista, tecnologista, contextualista, comunicacional, formalista, deconstructivista, fenomenologista. Algunas de ellas (comunicacional, tecnologista, fenomenologista y formalista) se encuentran más cercanas a lo que él denomina arquitectura débil. Débil en el sentido de Gianni Vattimo, desarrollado como concepto en "el pensamiento débil" o líquida, en el sentido de Zygmunt Bauman (2007), como parte de la "modernidad líquida".

4 Oficialmente denominada Unión de Repúblicas Socialistas Soviéticas, fue una federación constituida en 1922 que en el tiempo llegó a conformarse por 15 repúblicas socialistas (RSS de Armenia, RSS de Azerbaiyan, RSS de Bielorrusia, RSS de Estonia, RSS de Georgia, RSS de Kazajistan, RSS de Kirguistan, RSS de Letonia, RSS de Lituania, RSS de Moldavia, RSS de Rusia, RSS de Tayikistan, RSS de Turkmenistan, RSS de Ucrania y RSS de Uzbekistan). Se disolvió en el año de 1991, cuando contaba con una población de 293 millones de habitantes y una superficie de 22402200 km2.

5 Las isbas, construidas en base a madera, son las tipologías más recurrentes tanto en el hábitat rural como urbano. Otros tipos de viviendas son netamente rurales y se encuentran en zonas extremas, como el iglú, el chum, la yaranga, la yurta, la ail, la saklia.

Extraído de: https://es.rbth.com/cultura/80715-7-tipos-diferentes-de-vivienda-tradicional-rusa.

6 Se tomó en cuenta la propuesta de José Luis García del año 2015, que sitúa las etapas de la arquitectura soviética a partir de sus relaciones con los gobiernos y acontecimientos más importantes, desde la revolución bolchevique hasta el fin de la etapa soviética.

7 Joseph Stalin, líder de la Unión Soviética, se alió a los bolcheviques de Vladimir Lenin en el año 1903, como jefe operativo en el Cáucaso, convirtiéndose en Secretario General del Partido Comunista en 1922 y Jefe Supremo de la Unión Soviética en 1924 a la muerte de Lenin. Como líder enfrentó a los nazis derrotándolos en la batalla de Stalingrado (1942) y en la batalla de Kursk (1943) lo que significó el inicio del fin de la Alemania Nazi en la II Guerra Mundial (1939-1945). Gobernó como dictador de la URSS hasta su muerte en el año de 1953.

8 Conjunto de siete rascacielos construidos por orden de Joseph Stalin en el centro de Moscú, que imitarían a los rascacielos neoyorkinos de la época, entre las décadas de 1940 y 1950. Conmemorarían el VIII centenario de la ciudad (1947). Estos son: la Universidad Estatal de Moscú (1953), el hotel Ucrania (1955), el edificio de la Plaza Kudrinskaya (1954), el Ministerio de Asuntos Exteriores de Rusia (1953), el Hotel Leningrado (1953), el edificio de la Plaza de la Puerta Roja (1953) y el edificio de viviendas en Kotélnicheskaya Náberezhnaya (1952). El plan original contemplaba ocho proyectos, de los cuales el Palacio de los Soviets nunca se construyó.

9 Para autores como Jean Marie Chauvier (2005) estas condiciones no son válidas, tratando de demostrar mediante análisis cualitativos y cuantitativos que lo señalado sobre la sociedad rusa es una excesiva y tergiversada información por parte de occidente para desacreditar a la URSS. Chauvier no descarta una desaceleración económica y un modelo agotado que, sin embargo, estaba medianamente controlado.

10 Vladimir Putin asume la presidencia interina (19992000). Posteriormente es elegido y reelegido presidente (2000-2004, 2004-2008). Deja la presidencia y se sitúa como Primer Ministro (2008-2012), para posteriormente retomar la jefatura del Estado en un tercer periodo (2012-2018) a lo que se suma, actualmente, un cuarto periodo (2018-2024).

11 Montaner señala que entre 1990 y 2011, año en que se reedita su texto, La modernidad superada, se dieron cuatro cambios importantes a nivel general: la crisis ecológica, los grandes movimientos migratorios, el fenómeno de la globalización y el predominio de las tecnologías de la información y la comunicación.

12 El no lugar fue señalado por Marc Augé (1993) como lo indiferente, lo indeterminado y lo anónimo, lo que no puede definirse como espacio de identidad relacional o histórico. Estas características se dan en los espacios de tránsito (aeropuertos, autopistas, hoteles, estaciones de tren, etc.). Hans Ibelings (1998) a partir del acercamiento hacia el no lugar conceptualizaría el supermodernismo en la arquitectura; mientras Eduardo Prieto (2011) en La arquitectura de la ciudad global indicaría que definir el no-lugar como concepto de lo no simbolizado es errado desde el momento en que se realizan sobre espacios concretos y acotados.

13 David Moriente (2010) en: Poéticas arquitectónicas en el arte contemporáneo, establece una serie de relaciones entre el arte y la arquitectura desde 1970 hasta el 2008 encontrando condiciones estéticas para que la arquitectura se vuelva icónica y autosuficiente, poniendo énfasis crítico en la pérdida del lugar, de la historia y 
de lo social, a lo cual le correspondería la esencia de lo arquitectónico en la actualidad.

14 Estos grandes espacios cubiertos, con un macroclima interior controlable, se experimentan desde 1960 con las propuestas de Frei Otto, Buckminster Fuller, Kevin Roche, John Dinkeloo, entre otros. (Bernarderle, 1994, p. 118). Algo singular ocurre con el Centro Cultural Pompidou, como contenedor donde lo funcional y espacial puede sufrir libres alteraciones, haciendo de las máquinas y los servidores los elementos jerárquicos, a tal punto de referenciarse como la imagen central de la propuesta.

15 Esta simbiosis entre lo global y modos ornamentales de la arquitectura islámica lo hemos observado, también, en edificaciones de Kiev (Ucrania), ciudades del Emirato de Dubai, las ciudades turcas de Gorem y Estambul, ciudades del Emirato de Abu Dabi, Luxor, Aswan, Alejandría y El Cairo en Egipto, Jerusalén y Tel-Aviv en Israel, entre otras ciudades de Medio Oriente donde se profesa o existe influencia del islam. En Rusia se estima que la religión predominante es la ortodoxa (50\%) y la segunda es la musulmana (12-15\%).

16 Prieto (2011, p. 58) haciendo un análisis de Rem Koolhaas y su manera de pensar la arquitectura desde lo formal indicaría: "Si la ciudad nace del caos generado por la competencia simbólica, la arquitectura debe entenderse como una cuestión de referencias, de hitos semánticos donde predomina, frente al programa o la técnica, la forma artística del objeto. Si los programas cambian, si las funciones mutan a lo largo de la vida de los edificios, entonces es la apariencia exterior el único elemento estable dentro de la incertidumbre generalizada y son, por lo tanto, los aspectos formales los que garantizan el valor necesario de la arquitectura. Además, si la forma es independiente del programa interior, si puede ser, como gusta de repetir Koolhaas, ajena incluso a su contexto, no hay lenguajes o estilos que a priori sean esencialmente mejores que otros (...)."

17 Los cinco estadios construidos fueron: el Estadio Central Sindical con capacidad para 34800 espectadores (1934), el Estadio Central Lenin renombrado hoy Olímpico Luzhniki con capacidad para 100000 espectadores (1956), el Estadio Central de Kazan con capacidad para 30000 espectadores (1960), el Estadio Republicano de Spartak de Vladikavkaz con capacidad para 32464 espectadores (1962), el Estadio Kuban de Krasnodar con capacidad para 40000 espectadores (1980) y el Estadio Metallurg de Samara con capacidad para 40000 espectadores (1980).

Debido a que los estadios constantemente amplían o reducen su aforo, se ha tomado en cuenta la capacidad mayor durante la era soviética (1921-1991). Extraído de: https://es.wikipedia.org/wiki/Anexo:Estadios de f\%C3\%BAtbol_de_Rusia http://www.vsportclub.ru/ category/stadiony-i-sportkompleksy/centralnyj-stadion-profsoyuzov/o-stadione/istoriya/ https://www. sports.ru/football/91621326.html

Salvo el campeonato logrado en una incipiente y discutida Eurocopa, del año 1960, y dos esporádicos títulos de una competencia menor como la copa UEFA en los años 2004 por el CSKA Moscú y el 2007 por el F.K. Zenit San Petersburgo, no se han obtenido mayores logros en la alta competencia del fútbol ruso a nivel internacional. De igual modo las condiciones del clima no permiten la realización sostenida del campeonato durante los intensos meses de frío invernal, entre noviembre y abril.

18 Hay inconvenientes concretos con algunos estadios brasileros construidos para el Mundial 2014. El estadio Mané Garrincha de Brasilia, el Arena de Amazonia de Manaos, el estadio Das Dunas de Natal, el Arena Pantanal de Matto Grosso tienen grandes problemas de mantenimiento, debido a la poca actividad que en ellos se realiza, los altos costos de alquiler y la escasa asistencia de público. A esto se suman las denuncias de corrupción en torno a los presupuestos, adjudicaciones y construcción, tanto de los estadios como de los proyectos urbanos que formaban parte del conjunto, lo que perjudica seriamente su viabilidad.

19 Se revisaron las páginas web oficiales de las cuatro firmas mencionadas donde se pueden encontrar biografía de los socios y un listado de sus obras, con énfasis en las más importantes y premiadas, con explicaciones y discursos sobre la forma de encarar los proyectos. Además, páginas específicas sobre los estadios, entre ellas: https://es.fifa.com/news/ekaterinburgo-arena-2664687

20 Sochi es considerada, por excelencia, la ciudad rusa de veraneo, debido a su clima que varía en promedio entre los 20 grados como mínimo y 28 grados como máximo durante dicha estación. El invierno es más corto (4 meses) y no obstante estar la temperatura fluctuando entre los 3 y 11 grados, es bastante más confortable que las sedes del centro y norte de Rusia (entre ellas, Ekaterimburgo, Saransk y Moscú) donde los meses de invierno duran entre 6 y 8 meses, con temperaturas que fluctúan entre 0 y -17 grados. Se revisaron las páginas https://weather.com/es y https://www.accuweather. com/ para obtener información.

21 Helio Piñón criticaría este tipo de arquitectura efectista en su Teoría del proyecto (2006, p. 126) señalando: "Esta arquitectura no es tectónica -sino "tecnicosa"por lo mismo que no es visual -sino óptica-, ni formasino alegórica-, ni ordenada -sino regular o irregular-, que es lo mismo. En realidad, no es arquitectura, sino una mera gestión de lugares comunes de fácil digestión, a base de subrayar los sinsentidos más notorios con una exhibición de despilfarro -material y económico- que dé cuenta de lo excepcional de la propuesta."

22 Entre los primeros estadios que puedo recordar con asientos multicolores es el estadio Isidro Romero Carbo de la ciudad de Guayaquil en Ecuador, inaugurado el 26 de mayo de 1988.

23 Uno de los primeros estadios que buscaba romper con las anteriores tipologías de estadios de múltiples usos fue el Stade de France ubicado en Saint-Dennis en las afueras de Paris, construido para el Mundial de fútbol Francia 1998. Fue diseñado para obtener hasta 3 distintas capacidades, lo que permite que las tribunas puedan adquirir configuraciones diversas a través de medios mecánicos que las sitúan más cerca al campo de fútbol, aumentando su capacidad y también mejores ubicaciones. Cuando se dan otras actividades deportivas, como las de atletismo, las tribunas se repliegan.

24 Título del libro escrito en el 2012 por Mario Vargas Llosa donde se hace una crítica a la sociedad actual, en la que según el autor se han perdido los valores sociales y artísticos, que se ha visto reemplazada por una sociedad de consumo, ávida de entretenimiento. El título alude de igual modo al texto filosófico de Guy Debord, La sociedad del espectáculo, publicado en París en 1967. 


\section{Referencias bibliográficas}

Augé, M. (1993) Los no lugares. Espacios del anonimato. Barcelona, España: Editorial Gedisa.

Baumann, Z. (2007) Miedo líquido: la sociedad contemporánea y sus temores. Barcelona, España: Paidós

Bernardele, O. (2009) Del posmodernismo a la deconstrucción. Buenos Aires, Argentina: Universidad de Palermo-Liberia Técnica CP67.

Chauvier, J. M. (2005) La perestroika, veinte años después. Ediciones Cono Sur. 72, junio, 20-22.

Davies, C. (2011) Reflexiones sobre la arquitectura. Introducción a la teoría arquitectónica. Barcelona, España: Editorial Reverté.

De Solá Morales, I. (1998) Diferencias. Topografía de la arquitectura contemporánea. Barcelona, España: Gustavo Gili, S.A.

-(2000) La arquitectura débil. Arkinka. Lima, año 5, n. 55, 44-49.

Español, J. (2001) El orden frágil de la arquitectura. Colección Arquithesis, n. 9. Madrid, España: Fundación Caja de Arquitectos.

Fernández, R. (2000) El proyecto final. Montevideo, Uruguay: Editorial Dos Puntos.

Frampton, K. (2007) La megaforma como paisaje urbano. Arkinka. Lima, año 11, n. 134, 12-17.

García, J. L. (2015) Las cuatro etapas de la arquitectura soviética. 24 de febrero. Recuperado de: http:// www.seccion.es/arquitectura/las-cuatro-etapas-de-la-arquitectura-sovietica-3/

González Orna, G. M. (2017) El nacionalismo ruso como política de estado en la era de Putin. Sus efectos en la política antiterrorista del Cáucaso norte y Asia central de 1999 a 2008. Tesis de maestría en relaciones internacionales, Universidad Nacional de La Plata.

Hernández, C. (2010) La textura de la corteza. Teoría y crítica del proyecto arquitectónico. Valencia, España: General de Ediciones de Arquitectura.
Ibelings, H. (1998) El supermodernismo, Arquitectura en la era de la digitalización. Barcelona, España: Gustavo Gili.

Kahhat, F. (2018) Prefacio. En: Guía política Mundial de fútbol Rusia 2018. Lima, Perú: Aerolíneas Editoriales S.A.C.

Marcu, S. (2007) La geopolítica de la Rusia postsoviética: Desintegración, renacimiento de una potencia y nuevas corrientes de pensamiento geopolítico. En: Scripta Nova. Revista electrónica de geografía y ciencias sociales. Universidad de Barcelona. Vol. XI. Núm. 253, diciembre.

Montaner, J. M. (2011) La modernidad superada, Ensayos sobre arquitectura contemporánea. Barcelona, España: Gustavo Gili.

(2014) Sistemas arquitectónicos contemporáneos. Barcelona, España: Gustavo Gili.

Morales, J. (2019) Las relaciones internacionales en Rusia: desarrollo, enfoques y debates. En: Revista Española de Derecho Internacional. Sección ESTUDIOS. Vol. 71. Enero-junio, Madrid, 139-162.

Moriente, D. (2010) Poéticas arquitectónicas en el arte contemporáneo, 1970-2008. Tesis doctoral Universidad Autónoma de Madrid, Facultad de Filosofía y Letras, Departamento de Historia del Arte.

Muntañola, J. (2001) La arquitectura como lugar. BarceIona, España: Ediciones UPC.

Piñon, H. (2006) Teoría del proyecto. Barcelona, España: Ediciones UPC.

Prieto, E. (2011) La arquitectura de la ciudad global. Redes, no-lugares, naturaleza. Madrid, España: Editorial Biblioteca Nueva.

Rivas, B. (2018) Guía política Mundial de Fútbol Rusia 2018. Lima, Perú: Aerolíneas Editoriales S.A.C.

Todorov, T. (2000) Los dilemas de la memoria. Universidad de Guadalajara, México. Extraído de: http:// www.jcortazar.udg.mx/sites/default/files/TODOROV.pdf 


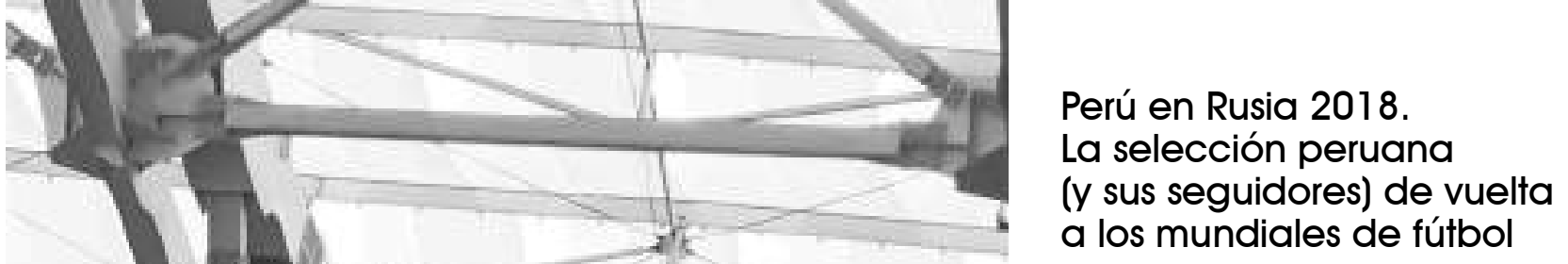

Luego de 36 años, la selección peruana de fútbol masculino volvió a clasificar a un mundial de mayores. Tras 18 partidos eliminatorios en Sudamérica, Perú disputó con Nueva Zelanda dos partidos de repechaje y pudo ganar el último cupo para Rusia 2018. Con ello la pasión por el fútbol se desató, aún más, en el país. Fue la quinta participación del Perú en un evento de esta importancia, tras los mundiales de Uruguay 1930, México 1970, Argentina 1978 y España 1982.

Las estadísticas señalan que aproximadamente 60,000 peruanos viajaron a Rusia para presenciar el campeonato $y$, eventualmente, asistir a los estadios donde compitió la selección nacional. Los partidos de Perú durante la primera fase del Grupo C fueron en las ciudades de Saransk, Ekaterimburgo y Sochi, contra Dinamarca, Francia y Australia.

El Estadio Mordovia Arena fue inaugurado para el Mundial 2018, en la ciudad de Saransk, capital de la República de Mordovia, en la región del Volga. Ekaterimbur Arena, también conocido como Estadio Central, fue remodelado para el mundial y se ubica en la ciudad de Ekaterimburgo, en el centro-oeste del país, en la parte oriental de la cordillera de los Urales, por lo tanto en el sector asiático de Rusia. Fisht Stadium, conocido como el Estadio Olímpico de Sochi, es un estadio multiuso en esta ciudad turística del mar Negro y fue construido para los Juegos de Invierno de 2014.

Ninguno de estos tres estadios superaba la capacidad de 50,000 espectadores, lo que no alcanzaba a dar cabida a todos los seguidores peruanos: queda claro que muchos no pudieron ingresar a los tres encuentros y que los desplazamientos entre las ciudades rusas tampoco eran cortos.

Los resultados de los partidos fueron, finalmente, dos derrotas contra Dinamarca y Francia y un triunfo contra Australia. Allí terminó la breve participación peruana en el mundial, aunque su hinchada fue elegida la mejor del mundo por la FIFA en setiembre de 2018, por su presencia y entusiasmo. La selección peruana de fútbol masculino había vuelto a los campeonatos mundiales de mayores y con ella una gran cantidad de hinchas ilusionados. (Nota del editor)

Hinchada peruana en el Estadio de Sochi.

Foto Adolfo Morey, 2018. 


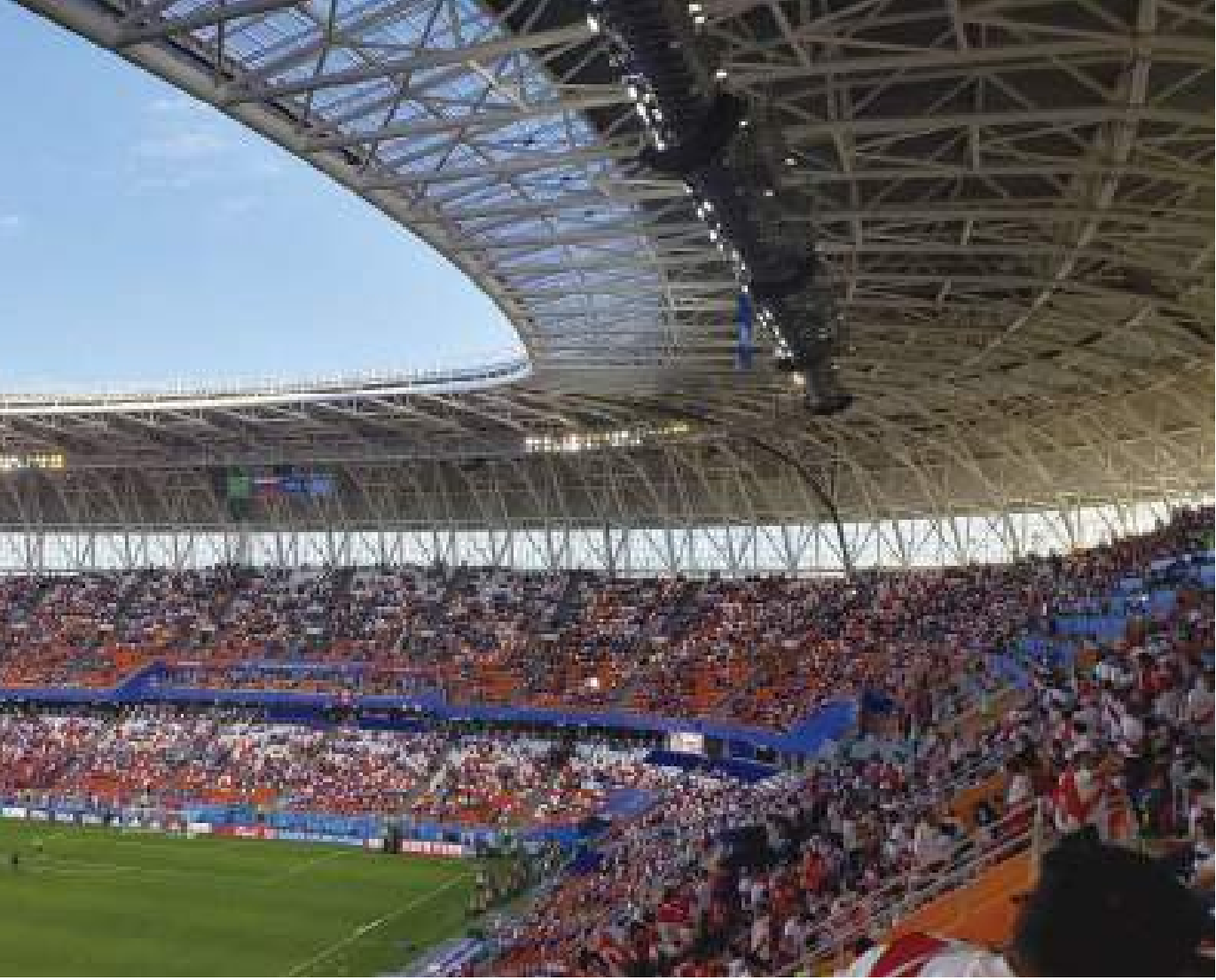

Estadio de Saransk. Mundial Rusia 2018. Fase de grupos, partido Perú Dinamarca.

Foto C. Castañeda, 16 de junio de 2018

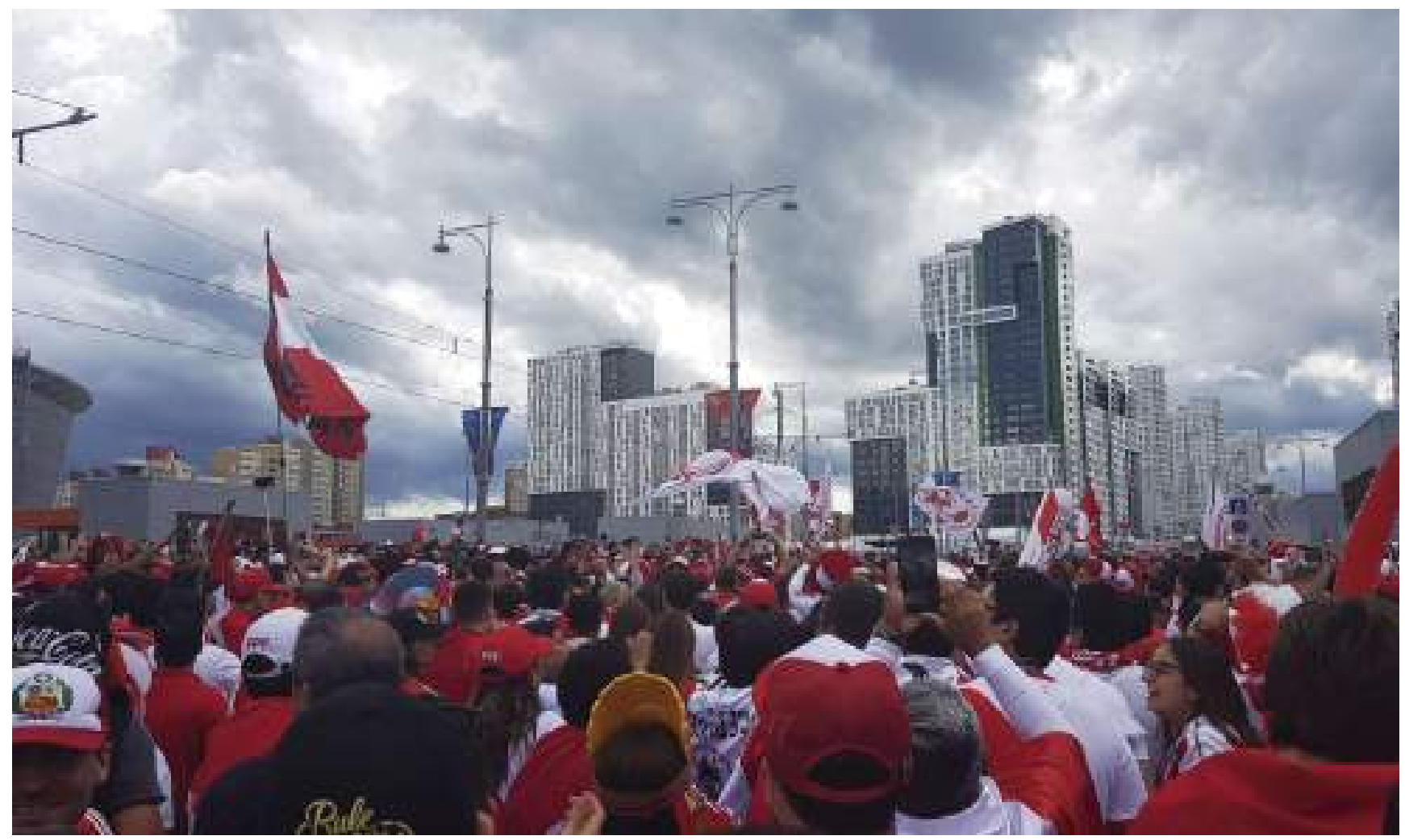

Exterior del Estadio de Ekaterimburgo. Mundial Rusia 2018. Hinchas peruanos, partido Perú Francia. Foto Adolfo Morey, 21 de junio de 2018. 


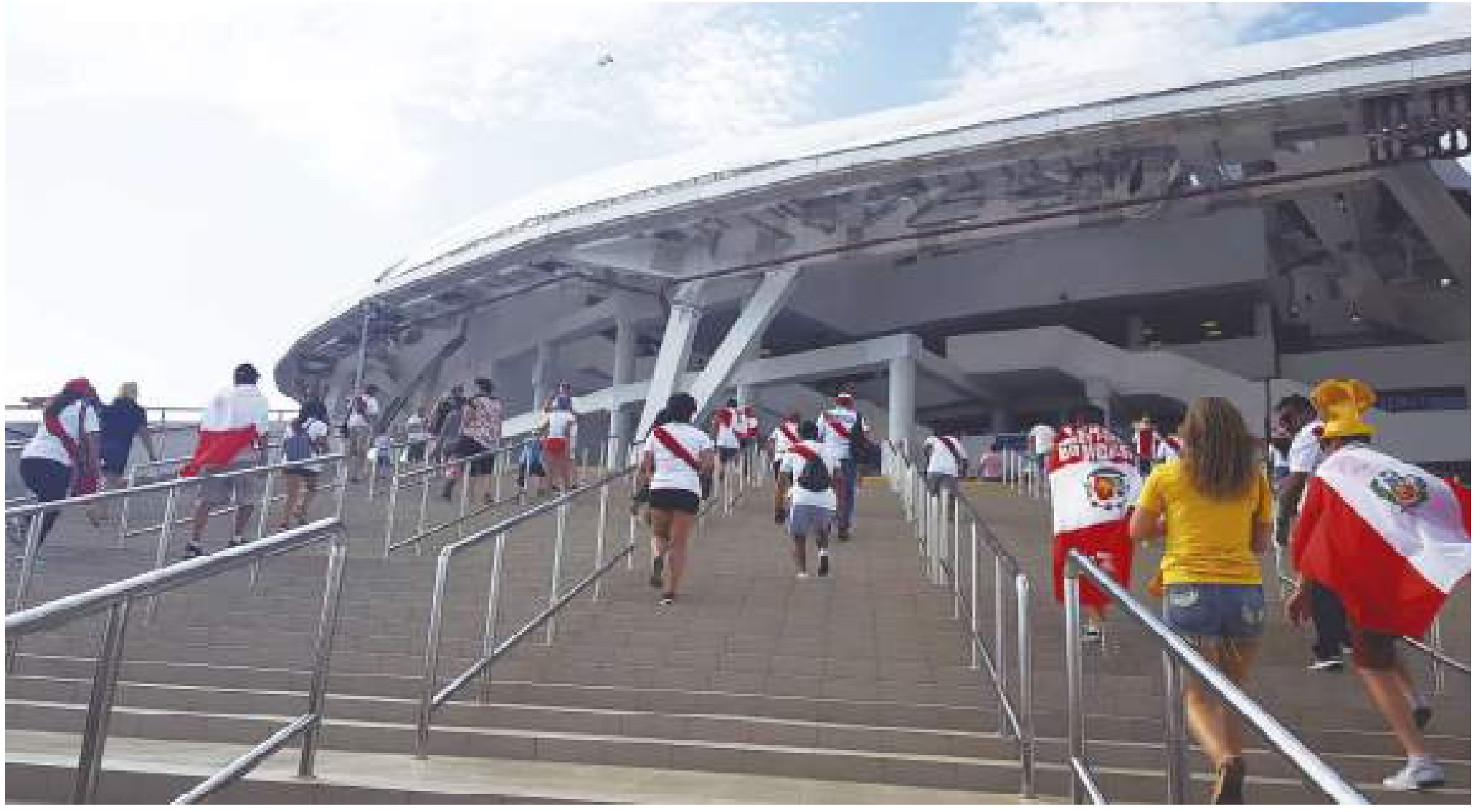

Estadio de Sochi. Mundial Rusia 2018. Ingreso al partido Perú Australia. Foto Adolfo Morey, 26 de junio de 2018

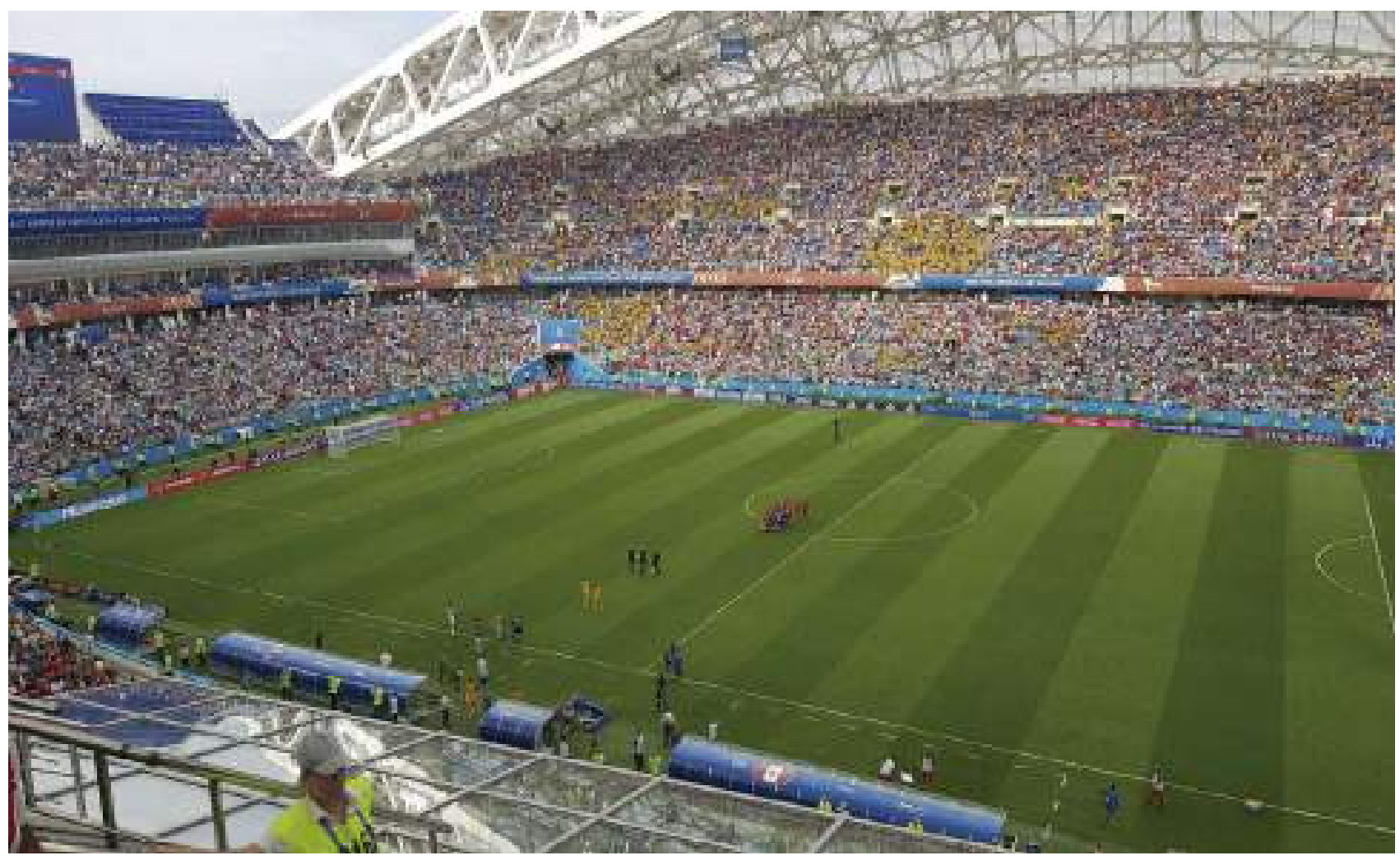

Estadio de Sochi. Mundial Rusia 2018. Perú Australia. Foto Adolfo Morey, 26 de junio de 2018. 
